\title{
El aprendizaje basado en escenarios como estrategia de desarrollo de competencias para afrontar el proceso de selección de personal
}

\author{
Silvia Nazareth Prieto Preboste \\ Directora de Innovación de la Universidad a Distancia de Madrid, UDIMA (España) \\ silvianazareth.prieto@udima.es | https://orcid.org/0000-0001-6902-9731 \\ José Manuel Chamorro Laborda \\ Profesor asociado de la Facultad de Ciencias Jurídicas de la \\ Universidad a Distancia de Madrid, UDIMA (España) \\ josemanuel.chamorro@udima.es | https://orcid.org/0000-0001-8478-6968
}

Este trabajo ha obtenido un Accésit del Premio Estudios Financieros 2021 en la modalidad de Educación y Nuevas Tecnologías.

El jurado ha estado compuesto por: don Manuel Area Moreira, don Julio Barroso Osuna, doña Ana GarcíaValcárcel Muñoz-Repiso, don José Hernández Ortega y don Javier de los Ríos Medina.

Los trabajos se presentan con seudónimo y la selección se efectúa garantizando el anonimato de los autores.

\section{Extracto}

Esta investigación versa sobre el diseño e implementación de un juego online de simulación, cuyo objetivo es ayudar al desarrollo de competencias en 54 estudiantes (hombres y mujeres) universitarios de grado y máster para afrontar con éxito un proceso de selección de personal. La base teórica en que se sustenta la herramienta desarrollada es el aprendizaje basado en escenarios $(\mathrm{ABE})$, que permite recrear diferentes pruebas de evaluación de competencias de un proceso de selección (dinámica de grupo, role playing y entrevista), propiciando que el estudiante conozca mejor dichas pruebas y, a través de un ejercicio de autoevaluación situacional, que reflexione sobre la importancia de desarrollar determinadas capacidades en su perfil.

Las conclusiones son muy positivas, ya que, tras participar en el juego, la mayoría consideró que sus conocimientos sobre cómo se desarrolla un proceso de selección habían mejorado, que el juego les permitía reflexionar sobre las debilidades y fortalezas de su perfil y que eran más conscientes de qué aspectos concretos debían mejorar para afrontar un proceso de selección.

Palabras clave: gamificación; simulación; aprendizaje basado en escenarios (ABE); selección de personal; entrevista; role playing; dinámica de grupo; e-learning; serious games.

Cómo citar: Prieto Preboste, S. N. y Chamorro Laborda, J. M. (2022). El aprendizaje basado en escenarios como estrategia de desarrollo de competencias para afrontar el proceso de selección de personal. Tecnología, Ciencia y Educación, 21, 49-80. https://doi.org/10.51302/tce.2022.650 


\title{
Scenario-based learning as a strategy to develop skills to cope with the process of personnel selection
}

\author{
Silvia Nazareth Prieto Preboste \\ José Manuel Chamorro Laborda
}

\section{Abstract}

This research describes the design and implementation of an online simulation game whose goal is to help develop skills in 54 university students (men and women) at the graduate and post-graduate levels, so they may successfully face a personnel selection procedure.

The theoretical basis that underpins this tool is scenario-based learning (SBL), which lets us recreate different skill assessment scenarios in a selection process (group dynamics, roleplay and interview) to provide students with better knowledge of these tests, and helps them to reflect on the importance of developing certain skills in their profile through a situational self-assessment. The conclusions are highly positive as after playing the game, most students believed that they had improved knowledge of how a selection process is conducted, that the game had allowed them to reflect on the strengths and weaknesses of their profile, and that they were more aware of the aspects to be improved in order to cope with a selection process.

Keywords: gamification; scenario-based learning (SBL); personnel selection; interview; roleplay; group dynamics; e-learning; serious games. 


\section{Sumario}

1. Introducción

2. Objetivos

3. Marco teórico

3.1. Las competencias en el ámbito laboral

3.2. Aprendizaje basado en escenarios (ABE)

4. Metodología

4.1. Características de la muestra

4.1. Diseño tecnopedagógico

4.2. Guionización y desarrollo de escenarios

4.2.1. Rutas por elección

4.3. Elaboración de guiones gráficos y grabación

4.4. Diseño e implementación en el aula virtual

4.5. Desarrollo de la actividad con los discentes

5. Análisis de los resultados obtenidos

6. Conclusiones y futuras líneas de investigación

Referencias bibliográficas

Anexo. Comentarios adicionales recibidos en la encuesta de autopercepción

Nota: los/las autores/as del artículo declaran que todos los procedimientos llevados a cabo para la elaboración de este estudio de investigación se han realizado de conformidad con las leyes y directrices institucionales pertinentes. Asimismo, los/las autores/as del artículo han obtenido el consentimiento informado (libre y voluntario) por parte de todas las personas intervinientes en este estudio de investigación. 


\section{Introducción}

Una de las principales preocupaciones de la universidad es la inserción en el mercado laboral de sus egresados/as. Para afrontar los procesos de selección con éxito, no es suficiente con los conocimientos propios de la titulación que hayan estudiado, sino

Una de las principales preocupaciones de la universidad es la inserción en el mercado laboral de sus egresados/as que es necesario dotarlos de conocimientos y habilidades, tales como discriminar entre diferentes técnicas de selección, conocer en profundidad sus características, comprender cuáles son los retos y objetivos de la entrevista, trabajar las debilidades y fortalezas del propio perfil para obtener un juicio positivo sobre su candidatura y saber manejar las emociones y los estados de ansiedad que puedan producirse en este tipo de procesos.

El departamento de bolsa de empleo de la universidad realiza diferentes acciones encaminadas a ayudar a los estudiantes en este trance, tales como la elaboración del curriculum vitae, para adecuarlo mejor a las posiciones deseadas por el participante, o el asesoramiento personalizado en la discriminación de las diferentes ofertas de empleo disponibles para el candidato. No obstante, en una universidad a distancia, en la que los egresados se sitúan en diferentes puntos geográficos de España o del mundo, no es viable realizar ensayos o entrenamientos especializados en los que el estudiante pueda practicar diferentes soluciones a las preguntas o situaciones que se dan en un proceso de selección al uso.

Por todo lo explicado con anterioridad, el objetivo de este estudio de investigación es encontrar una solución didáctica que ponga al alcance del estudiante la inmersión directa en las fases típicas de un proceso de selección de personal.

\section{Objetivos}

Este trabajo de investigación tiene como objetivo general el diseño de un recurso educativo, bajo la metodología del $A B E$, que permita contribuir, en un grupo piloto de estudiantes universitarios, al desarrollo de competencias para afrontar con éxito un proceso de selección de personal.

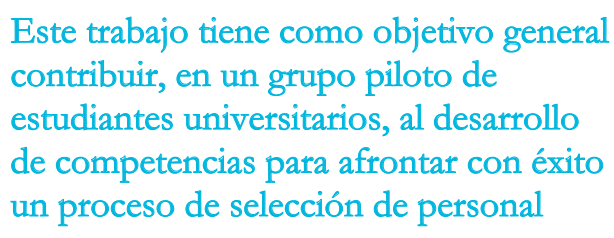

Este trabajo tiene como objetivo general contribuir, en un grupo piloto de estudiantes universitarios, al desarrollo de competencias para afrontar con éxito un proceso de selección de persona 
Se plantean los dos siguientes objetivos específicos:

- Recrear diferentes pruebas de evaluación de competencias en un proceso de selección para que, a través de un ejercicio de autoevaluación, se oriente al estudiante sobre la importancia de desarrollar determinadas capacidades en su perfil.

- Crear un entorno que permita al estudiante conocer mejor las pruebas asociadas a un proceso de selección para que consiga afrontarlo con mayor seguridad.

\section{Marco teórico}

\subsection{Las competencias en el ámbito laboral}

El verdadero impulso y auge del concepto de "competencia» se produce de la mano de David McClelland en 1973. El psicólogo de Harvard, conocido por muchos como «padre de las competencias», escribió el famoso artículo «Testing for competencies rather than intelligence», a partir del cual se inicia, según numerosos estudiosos (Mulder, 2007; Romeo y Yepes, 2005; Vossio, 2002; Zabala y Arnau, 2008), el camino de las competencias en el ámbito empresarial. McClelland introduce el concepto de «competencia» como una herramienta que permite pronosticar el rendimiento y el éxito en el ámbito laboral.

Una «competencia» es «una característica subyacente en una persona que está causalmente relacionada con el desempeño, referido a un criterio superior o efectivo, en un trabajo o situación» (Spencer y Spencer, 1993). En consecuencia, entendemos la competencia como un potencial de conductas adaptadas a una situación.

De acuerdo con esta definición, se habla de una característica subyacente porque la competencia es una parte profundamente arraigada en la personalidad del alumno que puede predecir su comportamiento en una amplia variedad de situaciones académicas o profesionales, destacando que está "causalmente relacionada» porque puede explicar o predecir su futuro desempeño profesional, tal y como apuntaba Flanagan (1954) al tratar sobre los incidentes críticos. Referido a un criterio significa que la competencia predice la actuación buena o deficiente del alumno utilizando un estándar de medida específico.

Las características subyacentes a la competencia son de diferentes tipos. Así, se puede hablar de motivación, rasgos de la personalidad, autoconcepto, conocimientos y habilidades. Las dos últimas características de la competencia, conocimiento y habilidades, son la parte más visible y fácil de identificar en estudiantes, mientras que las tres primeras, motivos, rasgos y autoconcepto, representan la parte menos visible, más profunda y central de la personalidad, según la teoría del iceberg (McClelland, 1973). 
La forma que adopte la competencia en el alumno estará condicionada por el contexto en el que se desplieguen sus conocimientos, habilidades, valores, etc. También estará condicionada por las propias situaciones de estudio o trabajo a las que se enfrente, con los requisitos y las limitaciones asociados a un entorno académico o profesional completo. Y la competencia también se moldea con la experiencia que el estudiante vaya acumulando dentro y fuera de la universidad.

En un reciente estudio llevado a cabo en 26 países, The Future of Jobs Report 20201, el World Economic Forum (2020) ha identificado las soft skills que serán indispensables en 2025 según los expertos. Capacidades como la resolución de problemas complejos, el pensamiento crítico, la creatividad, el liderazgo y la influencia, la resiliencia, la flexibilidad, la inteligencia emocional, la orientación al aprendizaje, las habilidades para orientar y negociar, así como la competencia digital y tecnológica, aparecen en el top 15 de las más necesarias.

Cuadro 1. Top skills en 2025

\begin{tabular}{|c|c|}
\hline 1. Analytical thinking and innovation & 9. Resilience, stress tolerance and flexibility \\
\hline 2. Active learning and learning strategies & 10. Reasoning, problem-solving and ideation \\
\hline 3. Complex problem-solving & 11. Emotional intelligence \\
\hline 4. Critical thinking and analysis & 12. Troubleshooting and user experience \\
\hline 5. Creativity, originality and initiative & 13. Service orientation \\
\hline 6. Leadership and social influence & 14. Systems analysis and evaluation \\
\hline 7. Technology use, monitoring and control & 15. Persuasion and negotiation \\
\hline 8. Technology design and programming & \\
\hline \multicolumn{2}{|c|}{$\begin{array}{l}\text { Nota: } 1 \text { (pensamiento analítico e innovación), } 2 \text { (aprendizaje activo y estrategias de aprendizaje), } 3 \text { (resolución de problemas comple- } \\
\text { jos), } 4 \text { (pensamiento crítico y análisis), } 5 \text { (creatividad, originalidad e iniciativa), } 6 \text { (liderazgo e influencia social), } 7 \text { (uso, seguimiento y } \\
\text { control de la tecnología), } 8 \text { (diseño y programación de tecnología), } 9 \text { (resiliencia, tolerancia al estrés y flexibilidad), } 10 \text { (razonamiento, } \\
\text { resolución de problemas e ideación), } 11 \text { (inteligencia emocional), } 12 \text { (resolución de problemas y experiencia de usuario), } 13 \text { (orienta- } \\
\text { ción al servicio), } 14 \text { (análisis y evaluación de sistemas) y } 15 \text { (persuasión y negociación). }\end{array}$} \\
\hline
\end{tabular}

1 https://www.weforum.org/reports/the-future-of-jobs-report-2020 
Conociendo que los empleadores buscan esas capacidades en los egresados, es importante potenciar la empleabilidad del alumnado mediante actividades de aprendizaje cuyo objetivo sea la toma de conciencia sobre la realidad del perfil profesional de cada estudiante.

El nuevo modelo de currículo que propone la Ley orgánica 3/2020, de 29 de diciembre, por la que se modifica la Ley orgánica 2/2006, de 3 de mayo, de educación (LOMLOE), que comenzará a implantarse en 2022, apuesta por trabajar ocho competencias avaladas por los objetivos de desarrollo sostenible de la Agenda 2030. De esas ocho, hay una competencia especialmente relacionada con las que menciona el World Economic Forum: la competencia personal, social y de aprender a aprender, definida como «la habilidad de reflexionar sobre uno mismo, gestionar el tiempo y la información eficazmente, colaborar con otros de forma constructiva, mantener la resiliencia y gestionar el aprendizaje a lo largo de la vida».

Otros modelos, con base en las directrices sobre el tema del Espacio Europeo de Educación Superior, clasifican como competencia genérica (o transversal, para algunos autores) aquellas que constituyen una parte fundamental del perfil profesional y del perfil formativo de la mayoría de las titulaciones. Están relacionadas con cualidades que se asocian a la formación universitaria e incluyen un conjunto de habilidades cognitivas y metacognitivas, conocimientos instrumentales y actitudes consideradas valiosas en la sociedad del conocimiento. Es importante que sean trabajadas en todas las asignaturas o adquiridas con independencia de las materias en las que se trabajen (Yániz y Villardón, 2006).

En consecuencia, para favorecer el desarrollo y el crecimiento del estudiante en las competencias consideradas en el perfil de cada titulación deben tomarse las actuaciones profesionales como punto de partida, desarrollando la formación del alumno como un todo en el que tienen cabida conocimientos, habilidades, actitudes y valores. Este hecho justifica que deba acudirse a diferentes modalidades y métodos de enseñanza, diseñando actividades innovadoras y diferenciales que sean capaces de provocar cambios en los comportamientos mediante el uso y la recreación de ambientes virtuales.

\subsection{Aprendizaje basado en escenarios (ABE)}

El $A B E$ es uno de los enfoques actuales que refuerza la obtención de un aprendizaje significativo dentro de un contexto auténtico. Según Clark y Mayer (2012), el aprendizaje electrónico basado en escenarios (AEBE) es un entorno de aprendizaje inductivo, diseñado para acelerar la adquisición de habilidades, en el que el alumno asume el papel de un actor que responde a una tarea o desafío de trabajo real; precisamente esta metodología es de las

Tecnología, Ciencia y Educación, 21 (enero-abril 2022), pp. 49-80 
que mejor se adaptan al aprendizaje de tareas estratégicas que requieren juicio y adaptación a cada nueva situación. En el uso de escenarios o entornos situacionales de aprendizaje, el «aprender haciendo" prima sobre la adquisición de conocimientos en sí misma (Del Rosario, 2013; Schank, 1997; Schank y Cleary, 1995), siendo especialmente propicio para los alumnos, en particular a la hora de adoptar soluciones en situaciones de indecisión o cuando se desconocen determinados detalles (Hursen y Fasli, 2017).

\begin{abstract}
$\mathrm{El} \mathrm{ABE}$ es uno de los enfoques actuales que refuerza la obtención de un aprendizaje significativo dentro de un contexto auténtico. [...] precisamente esta metodología es de las que mejor se adaptan al aprendizaje de tareas estratégicas que requieren juicio y adaptación a cada nueva situación
\end{abstract}

Especialmente interesante resulta el diseño de los escenarios. Varios autores coinciden en la importancia de que estos sean extraídos de situaciones reales, pues, de esa manera, tendrán la complejidad requerida para valorar competencias y habilidades (Hursen y Fasli, 2017; McLaren, 2008). A pesar de su realismo, estos escenarios «no prevén lo que pasará, sino que describen futuros alternativos posibles y, como tales, permiten medir y elegir alternativas de desarrollo» (Porter, 2004, citado por Martínez, 2009), siendo flexibles ante el error del estudiante, como parte del proceso de aprendizaje, y permitiéndole encontrar más de una solución a los dilemas que se plantean. Además, los escenarios no solo deben ofrecer las experiencias de aprendizaje más realistas, sino que deben ser divertidos y agradables (Hursen y Fasli, 2017); por este motivo, la experiencia objeto de esta investigación se plantea como un juego de simulación.

En la revisión bibliográfica realizada no se ha encontrado ningún ejemplo de uso del ABE como herramienta de preparación para realizar un proceso de selección de personal. Entre los trabajos encontrados destaca el uso de esta metodología en ciencias técnicas: circuitos eléctricos (Papadimitriou, 2012), laboratorios virtuales (Breakey et al., 2008; Muhamad et al., 2012) o promoción de la educación en ciencia, tecnología, ingeniería y matemáticas (science, technology, engineering and mathematics [STEM]) en educación primaria (Proudfoot y Kebritchi, 2017). Existen trabajos en el ámbito de las ciencias de la salud (Cant y Cooper, 2010; Steadman et al., 2006) y de la educación (Hursen y Fasli, 2017; Martínez, 2009; Del Rosario, 2013). En el área de competencias en el ámbito laboral, destacan Clark y Mayer (2012), que desarrollan un modelo de diseño de AEBE para la adquisición de competencias laborales en distintas industrias (veterinaria, ingeniería automotriz, ventas), y Errington (2011), que se centra en el uso del ABE como complemento de las prácticas laborales de la titulación y acerca al estudiante a la realidad de la profesión elegida a través de la construcción y deconstrucción de escenarios acompañados de reflexión estratégica, contribuyendo a construir la identidad profesional de los alumnos y mejorando sus aptitudes para la empleabilidad.

La aplicación del ABE al entorno de aprendizaje electrónico implica dificultades adicionales, que debían tenerse en cuenta, tales como la interfaz o las opciones de navegación. 
Siguiendo a Clark y Mayer (2012), existen cuatro opciones (véase cuadro 2): escenarios ramificados, controlado por menú, objeto activo a pantalla completa o mundos virtuales. En la primera fase del proyecto, que ocupa la presente investigación, se escogieron los escenarios ramificados al presentar una dificultad técnica menor y prestarse mejor a progresiones lineales, como habilidades interpersonales y tareas que se desarrollan con el tiempo (Clark y Mayer, 2012).

\section{Cuadro 2. Opciones de navegación e interfaz del AEBE}

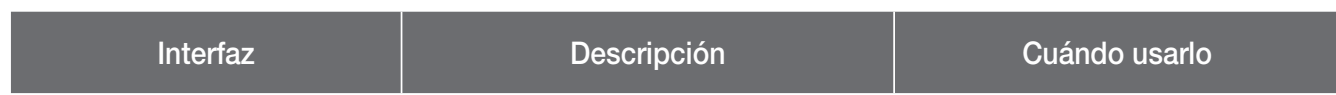

Escenarios ramificados. El alumno responde a situaciones seleccionando entre tres o cuatro opciones de texto.

\begin{tabular}{|c|c|c|}
\hline Controlado por menú. & $\begin{array}{l}\text { El alumno selecciona elementos del } \\
\text { escenario de un menú en pantalla } \\
\text { persistente. }\end{array}$ & $\begin{array}{l}\text { En escenarios moderadamente } \\
\text { estructurados en los que el alum- } \\
\text { no tiene que elegir opciones de } \\
\text { un menú de elementos que se } \\
\text { incluyen en el escenario. }\end{array}$ \\
\hline $\begin{array}{l}\text { Objeto activo a pantalla com- } \\
\text { pleta. }\end{array}$ & $\begin{array}{l}\text { El alumno selecciona objetos en pan- } \\
\text { talla para acceder a los elementos } \\
\text { del escenario. }\end{array}$ & $\begin{array}{l}\text { En escenarios menos estructura- } \\
\text { dos cuando las metas de apren- } \\
\text { dizaje se enfocan tanto en el } \\
\text { proceso como en las soluciones. }\end{array}$ \\
\hline Mundos virtuales. & $\begin{array}{l}\text { Los alumnos son libres de interactuar } \\
\text { con el medioambiente o con otros. }\end{array}$ & $\begin{array}{l}\text { En la coordinación entre varios } \\
\text { jugadores en un entorno virtual } \\
\text { 3D. }\end{array}$ \\
\hline
\end{tabular}

En escenarios alta o moderadamente estructurados que se pueden resolver con rutas de respuesta lineal.

Fuente: Clark y Mayer (2012)

\section{Metodología}

\subsection{Características de la muestra}

Para realizar la investigación se contó con el universo de estudiantes matriculados en las titulaciones de grado y máster de la universidad en el momento de la investigación, de los cuales jugaron el juego de manera voluntaria 74 sujetos y participaron en la encuesta de autopercepción un total de 54 (36 hombres y 18 mujeres). 
Figura 1. Distribución de la muestra en función de la edad de los participantes

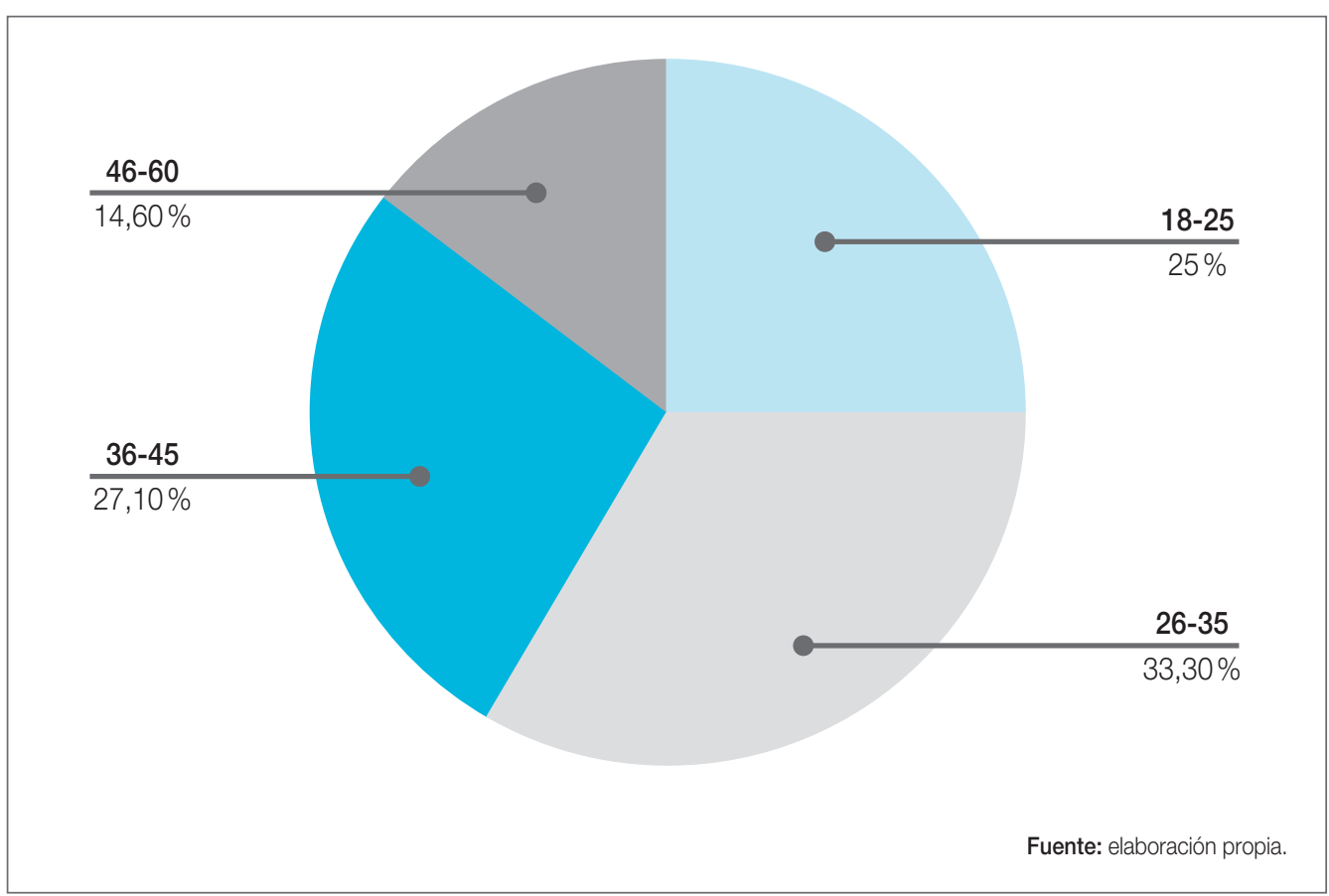

En la figura 1 puede observarse la distribución de la muestra en función de la edad. Aunque inicialmente se entendía que esta actividad llamaría la atención del público más joven e inexperto, la realidad es que fue realizada voluntariamente por sujetos de todas las franjas de edad, siendo el mayor porcentaje de intervención el correspondiente a los estudiantes en la franja de edad de 26 a 35 años.

\subsection{Diseño tecnopedagógico}

La materialización de la actividad de AEBE se llevó a cabo en cuatro fases, distribuidas en un proceso circular de mejora constante de la misma (véase figura 2).

En primer lugar, se diseñaron los tres escenarios en que se desarrollaría la actividad y que se corresponden con tres fases del proceso de selección:

- Dinámica de grupos.

- Role playing.

- Entrevista por competencias. 
En esta fase también se redactaron los guiones de las diferentes escenas que formarían parte de la actividad, en formato vídeo, así como las preguntas que debía responder el estudiante para alcanzar los objetivos de aprendizaje propuestos. En la segunda fase, y basados en los guiones redactados en la etapa anterior, se elaboraron los guiones gráficos que sirven de directriz para la grabación de los vídeos asociados a la actividad. En la tercera fase, se implementó la actividad propiamente dicha en el aula virtual a través de la herramienta H5P. Por último, la cuarta fase consistió en la realización de la actividad con los discentes. Al finalizar el juego se les preguntó por diferentes aspectos de la dinámica, con un doble objetivo:

- Verificar en qué medida se cumplieron los objetivos de la presente investigación.

- Conseguir una retroalimentación de los participantes que permitiera la repetición de fases anteriores para ajustar y afinar el juego.

Figura 2. Fases del diseño

FASE IV

Desarrollo de la actividad con los discentes

FASE III

Diseño e implementación en el aula virtual

\section{FASE I}

\section{Guionización y \\ desarrollo de escenarios}

FASE II

Elaboración de guiones gráficos y grabación

Fuente: elaboración propia. 


\subsection{Guionización y desarrollo de escenarios}

Adaptando la estructura propuesta por Nickson (2010), y haciéndolos corresponder con tres fases del proceso de selección, se desarrollaron tres escenarios principales que incluían, a su vez, cada uno de ellos, varios escenarios secundarios. La superación de cada uno de estos escenarios dio paso al siguiente, siendo la recompensa final la contratación por parte de la hipotética empresa (véase figura 3).

Figura 3. Dimensionalidad competencial de los escenarios

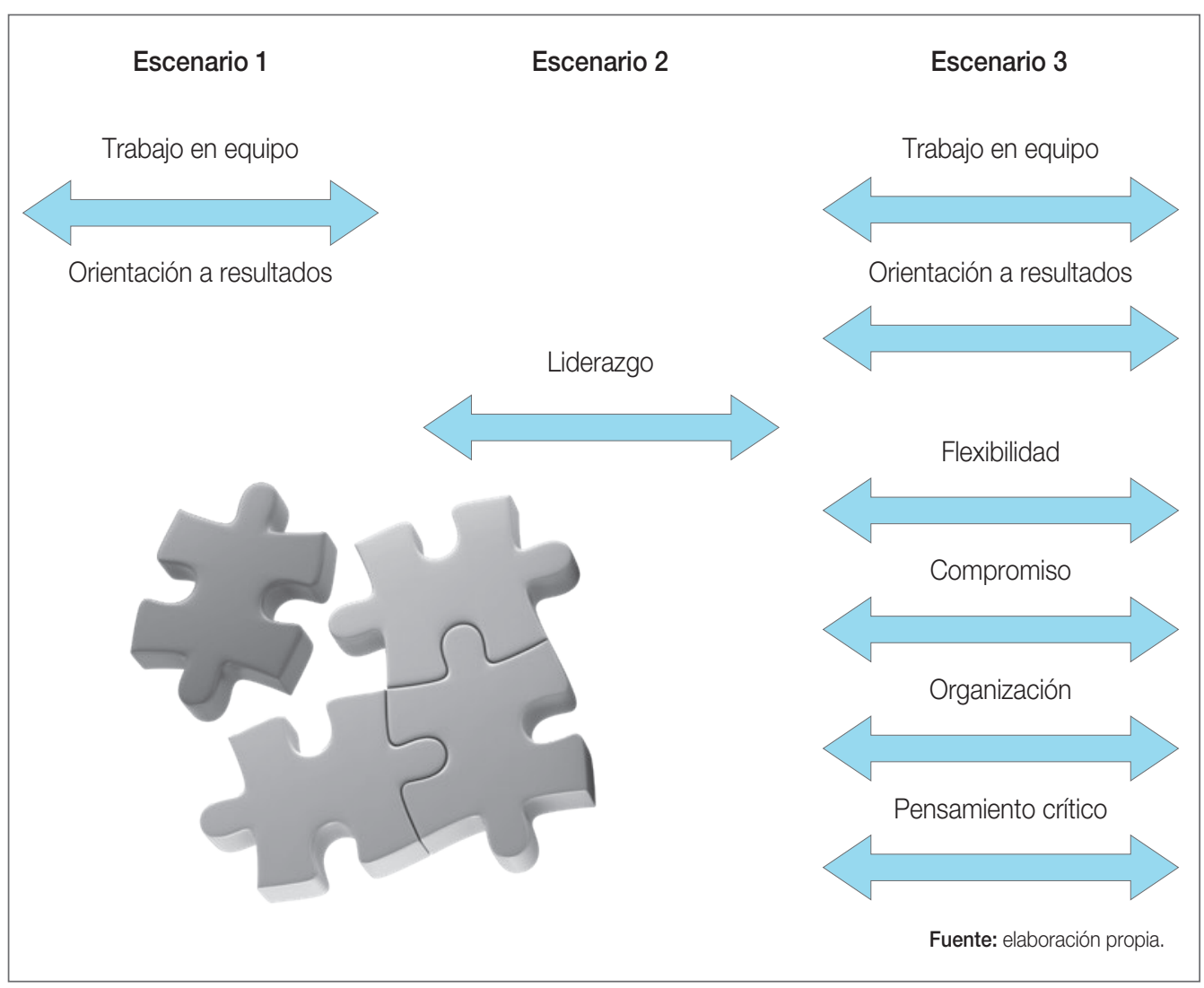

Cada uno de los ocho escenarios principales de la dinámica plantean una situación relacionada con las competencias anteriormente mencionadas en la que la decisión sobre la actuación es indicativa de la evidencia, en diferente grado, de la competencia. La mayoría de las situaciones están pensadas para medir la forma en que el alumno muestra su capacidad para trabajar en equipo y orientarse a resultados. 


\section{Escenario 1. Dinámica de grupo}

Escenario. El estudiante ha llegado a la fase final, junto con otros tres candidatos, de un proceso de selección. En los siguientes minutos de desarrollo del juego va a tener la oportunidad de participar en tres pruebas diferentes, cuyo objetivo es la evaluación de las competencias asociadas al perfil de talento que se busca. La primera de ellas es una dinámica de grupo, en la que interactuará con otros tres candidatos para resolver entre todos un reto en común propuesto por el evaluador.

Justificación de la elección. El trabajo en equipo influye en los resultados de una empresa. Cuando los trabajadores colaboran, la información fluye rápidamente, se obtienen resultados más innovadores y mejora la competitividad empresarial. El estudio realizado por Carr y Walton (2014) demostró que el trabajo en equipo disminuye en un $64 \%$ los bloqueos individuales, reduce la fatiga, facilita el éxito de los proyectos y aumenta el compromiso organizacional. Con el diseño del escenario que simula una dinámica de grupo se pretende que el alumno comprenda la importancia que tiene dicha competencia a la hora de potenciar la empleabilidad de su perfil professional.

Qué problemas se plantean y por qué son importantes. Las situaciones recreadas en la dinámica de grupo buscan que el alumno se familiarice con una serie de comportamientos habituales en una prueba evaluativa de tipo grupal en la que el objetivo es identificar capacidades como el trabajo en equipo, la solución de problemas y la orientación a resultados. De igual forma, al tratarse de la primera prueba del proceso de selección simulado, ayuda a tomar contacto con dicho contexto.

\section{Escenario 2. Role playing}

Escenario. Esta prueba, de carácter individual, consiste en simular una interacción con el evaluador, relacionada con un contexto profesional. Al estudiante se le propone que es un responsable del Departamento de Servicio al Cliente, que lleva seis meses en el puesto y que tiene a su cargo un equipo de cinco personas. Se acerca el cierre del trimestre y hay que analizar cómo están los objetivos que se marcaron para este periodo y si el desempeño del equipo ha estado a la altura de lo esperado. En líneas generales, el equipo ha cumplido la mayoría de los objetivos fijados, salvo el que tiene que ver con el número de incidencias resueltas en plazo, en el que se han quedado cerca, pero que no se ha alcanzado. Va a tener una breve reunión de seguimiento con su jefe, en la que se va a hablar de ello, ya que necesita recabar datos para el próximo comité de dirección. El estudiante debe estar preparado y dar la información adecuada en sus respuestas.

Justificación de la elección. Un role play, o técnica de dramatización, busca identificar en el evaluado comportamientos directamente relacionados con diferentes capacidades asociadas a procesos de interacción con personas en los que prima el componente relacional. Suele ser una prueba muy útil para medir conductas asociadas a la forma en que se gestiona un equipo, en especial, al estilo de liderazgo. Hoy en día, más que nunca, las empresas necesitan profesionales con habilidades sociales, trabajo en equipo y liderazgo. Según la encuesta The Future of Jobs Report 2020*, publicada por el World Economic Forum, el liderazgo y la influencia social se encuentran en la sexta posición en el ranking de los 15 top skills para 2025.

Qué problemas se plantean y por qué son importantes. A diferencia de la prueba anterior, en este caso, el alumno debe situarse en un escenario en el que interacciona directamente con otra persona, que asume el papel de su superior directo, situación que se da con frecuencia en un entorno empresarial. El resultado 
depende únicamente de su rendimiento individual, expresado en forma de respuestas en el marco de una conversación simulada con otra persona. De esta forma, su aproximación al entendimiento de la responsabilidad que tiene hacia su equipo, como supuesto gestor de un departamento, será la que marque dicho resultado. Cada uno de los seis escenarios principales planteados en el role play apuntan directamente a la recogida de evidencias comportamentales asociadas a la forma en que el alumno ejerce o ejercerá su liderazgo sobre el equipo.

\section{Escenario 3. Entrevista por competencias}

Escenario. En este escenario, el estudiante sigue compitiendo con otros candidatos, al igual que en las pruebas anteriores, y ahora se someterá de forma individual a las preguntas que le formule el entrevistador. Se le recomienda que, en cada una de las situaciones a las que se va a enfrentar, responda de acuerdo con su estilo de comportamiento y que no intente proyectar una imagen de sí mismo que no se ajuste a la realidad. Dependiendo de la idoneidad de la respuesta aportada, avanzará a la siguiente pregunta.

Justificación de la elección. Una entrevista por competencias tiene como objetivo indagar en el perfil del candidato para identificar el nivel en el que se encuentra cada competencia. Combina repaso curricular y focalización en incidentes críticos acontecidos en la trayectoria académica y profesional, es decir, conductas positivas y negativas pasadas y presentes, predictoras del desempeño exitoso futuro. Parte del «principio de consistencia de la conducta", por lo que trata de predecir las conductas futuras en el puesto de trabajo a partir de la evaluación de las conductas pasadas (Chorogwicka y Moscoso, 2007; Janz, 1982, 1989; Motowidlo et al., 1992; Salgado y Moscoso, 2001, 2002, 2011). Las revisiones metaanalíticas realizadas hasta el momento respaldan la utilización de esta técnica, al tratarse de una de las más fiables y con mayor capacidad predictiva (Salgado y Moscoso, 1995, 2006; Salgado, Gorriti y Moscoso, 2007; Salgado, Moscoso y Gorriti, 2004; Taylor y Small, 2002), tal y como se recoge en el cuadro I.

\section{Cuadro I. Fiabilidad y validez de los métodos de selección de personal}

\begin{tabular}{l|c|c|}
\hline \multicolumn{1}{c|}{ Método } & Fiabilidad & Validez operativa \\
\hline Entrevista conductual estructurada. & 0,83 & 0,63 \\
\hline Exámenes (test) de conocimientos. & $0,80,45$ \\
\hline Assessment center-Simulaciones. & 0,70 & 0,37 \\
\hline Entrevistas convencionales estructuradas. & 0,65 & 0,33 \\
\hline Referencias personales. & 0.60 & 0,26 \\
\hline Valoración de méritos y formación. & 0,80 & 0,18 \\
\hline Entrevistas no estructuradas. & 0,50 & 0,14 \\
\hline
\end{tabular}

Fuente: Salgado y Moscoso (2008, p. 18). 
Qué problemas se plantean y por qué son importantes. Estamos ante la que, posiblemente, sea la técnica más utilizada en un proceso de selección y a la que, con toda seguridad, cualquier alumno se haya enfrentado en alguna ocasión o vaya a enfrentarse a corto plazo. Por ello, es importante entender que es, de las tres pruebas simuladas, la que tiene una importancia mayor, pues puede emplearse para contrastar lo valorado en otras pruebas como las anteriormente realizadas. Como por duración suele ser la más larga, durante una entrevista por competencias se pueden sondear varias capacidades que se consideren relevantes para un eficaz desempeño. En este caso, las diferentes situaciones replicadas apuntan a competencias diversas, todas presentes en los rankings de preferencia por parte de empresas empleadoras. Recordemos que el objetivo de este proceso de selección simulado no es un puesto en particular, sino obtener una evaluación del potencial del participante. Por ello, en cada uno de los nueve escenarios que componen esta última prueba, se recrean interacciones de pregunta-respuesta que pretenden identificar comportamientos asociados a orientación a resultados, trabajo en equipo, flexibilidad, compromiso, organización y pensamiento crítico.

* https://www.weforum.org/reports/the-future-of-jobs-report-2020

\subsubsection{Rutas por elección}

En cada uno de los escenarios, las rutas posibles salen de la combinatoria entre las alternativas que puntúan. En las figuras 4 y 5 se ejemplifican dos rutas:

- Ruta correcta. Todas las respuestas son las idóneas.

- Ruta alternativa 1. Todas las respuestas son la segunda mejor opción.

Si se elige una alternativa que no puntúa, el valor es 0 , aunque en las siguientes elecciones se elija una de las dos válidas. El rango de resultados de cada uno de los escenarios principales iría de 0 a 12 puntos en el role playing y de 0 a 16 puntos en la dinámica de grupo y en la entrevista por competencias. Los rangos de puntuación total son los siguientes:

- $39-43$ puntos $=90-100 \%$ ajustado.

- 32-38 puntos $=75-89 \%$ ajustado.

- 22-37 puntos $=50-74 \%$ ajustado. 
Figura 4. Ruta correcta para el escenario «Entrevista por competencias»

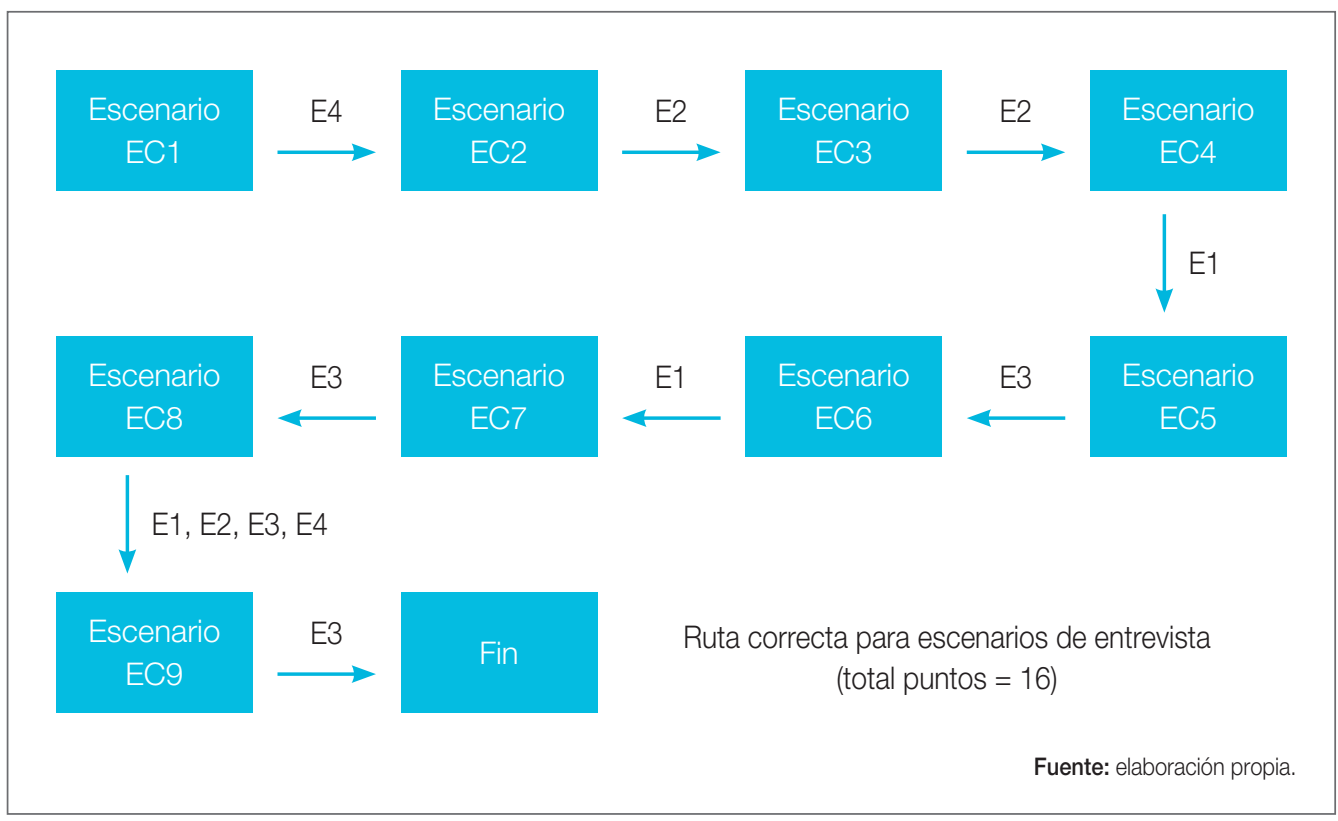

Figura 5. Ruta alternativa 1 para el escenario «Entrevista por competencias»

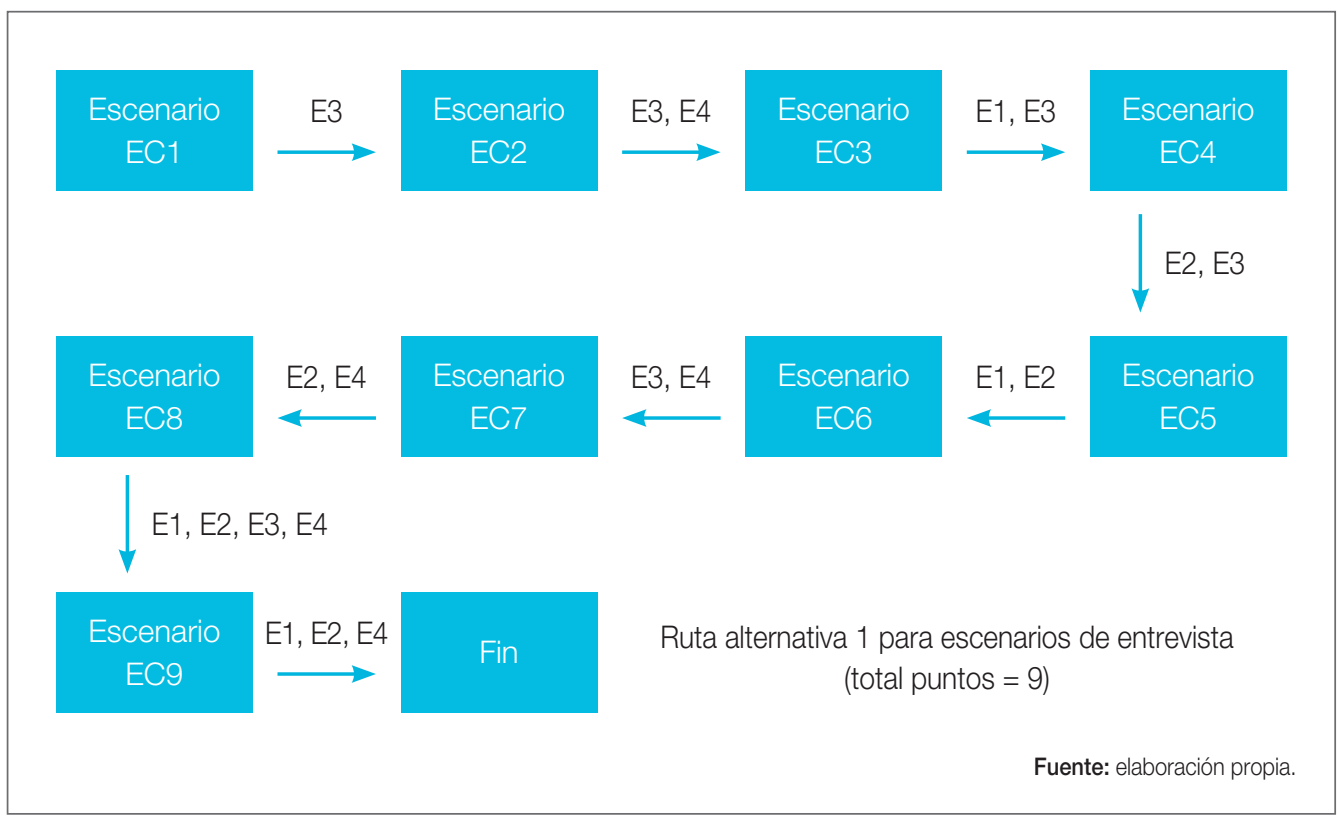




\subsection{Elaboración de guiones gráficos y grabación}

Una vez escritos los guiones, y para facilitar la coordinación con el departamento de audiovisuales de la universidad, se elaboraron tres guiones gráficos o storyboards. El storyboard consiste en una serie de pequeños dibujos ordenados en secuencia de las acciones que se van a filmar o grabar, de manera que la acción de cada escena se presenta en términos visuales (Medrano, 2009).

Siguiendo a Carrero (2011), algunas de las ventajas de elaborar un storyboard son:

- Simboliza un puente entre lo escrito (el guion) y lo audiovisual (el plano).

- Facilita la captación del lenguaje audiovisual (vídeo + sonido).

- Evita cometer posibles errores no previstos en el guion, ya sea en el texto o en la elección de los planos de cámara.

- Es un recurso útil para la medición previa del tiempo que durará la producción.

En la presente investigación, el storyboard no se basó en dibujos, sino en imágenes que sirvieran de inspiración y de guía para organizar todo el proceso de la producción audiovisual posterior. Se incluían también anotaciones sobre aspectos que había que tener en cuenta a la hora de implementar los vídeos en la herramienta H5P, durante la fase de diseño e implementación.

En la fase de producción audiovisual se grabaron un total de 60 vídeos de una duración media de 20 segundos. La mayor parte de los vídeos se grabaron con cámara subjetiva. La cámara subjetiva o plano subjetivo (POV² shot) muestra lo que ven los ojos del personaje, favoreciendo la identificación con él. La escena se ve a través de los ojos del personaje y la cámara se mueve con él. De esta manera se pretende dar mayor realismo a la escena y situar al estudiante como actor principal dentro de la misma.

\subsection{Diseño e implementación en el aula virtual}

Como punto de partida para la creación de la implementación del juego en el aula virtual se tomó el conjunto de actividades de H5P, que es una herramienta de código abierto que permite crear actividades interactivas e incrustarlas en páginas web. Se eligió esta herramienta por las siguientes características destacables (Romero et al., 2019):

2 Point of view (POV). 
- Admite diferentes tipos de contenidos. El sitio web de $\mathrm{H}^{2} \mathrm{P}^{3}$ incluye hasta 46 tipos de contenidos diferentes para la creación de actividades interactivas. Algunos de los más destacados son el vídeo interactivo, el tour virtual $360^{\circ}$ o el juego de memoria.

- Fácil integración. H5P se basa en HTML5, y, por tanto, se puede incrustar en cualquier página web. Además, en la versión 3.9 de Moodle (lanzada el 15 de junio de 2020), esta herramienta entró a formar parte del núcleo. Esto facilitaba la implementación de la actividad, pues Moodle es el learning management system (LMS) en el que está montado el campus virtual de la universidad y su inclusión en el núcleo permitía la creación de la actividad directamente desde el LMS, así como recopilar en la plataforma toda la información sobre la interacción de los estudiantes con la actividad.

- Permite un registro detallado de interacciones. H5P ofrece información detallada sobre la interacción del estudiante con las actividades y registra tanto sus respuestas como el tiempo empleado en responderlas. Esto permite un análisis muy completo utilizando técnicas de analíticas de aprendizaje.

Dentro de las actividades que incluye la herramienta H5P, se escogió, para la implementación de este proyecto, la ramificación de escenarios o branching scenario. Esta actividad, como se describe en el sitio web oficial de $\mathrm{H}_{5} \mathrm{P}^{4}$, permite a los usuarios crear dilemas, escenarios de aprendizaje autorregulados por el estudiante y otros tipos de aprendizaje adaptativo. El uso de esta actividad admite cualquiera de estos contenidos:

- Presentación del curso. Presentación de diapositivas en la que podemos mezclar texto e imágenes en diferentes marcos a través de los cuales el alumno avanzará o retrocederá. Incluso permite incluir preguntas de comprensión o motivación para que sea interactivo.

- Texto. Explicación que queremos incluir de forma aislada.

- Imagen. Muestra al alumno una imagen o fotografía 2D.

- Hotspots de imagen. En la imagen pueden agregarse puntos que, al ser pulsados, aportan información contextual o descriptiva.

- Vídeo. Se puede incluir un vídeo que el alumno deba obligatoriamente ver para pasar a la siguiente sección.

- Vídeo interactivo. Este tipo de vídeo permite agregar preguntas de diferentes tipos durante la reproducción del mismo.

\footnotetext{
3 https://h5p.org/

4 https://h5p.org/branching-scenario
} 
- Pregunta de ramificación. Permite plantear preguntas con distintas alternativas al alumno y asignar diferentes trayectorias o ramificaciones según su respuesta.

Para la implementación del juego se emplearon fundamentalmente los recursos de imagen, hotspots de imagen y vídeo que se mostraban al estudiante de acuerdo con sus respuestas en las preguntas de ramificación. Esto facilitaba la creación de un árbol de aprendizaje adaptativo (véase figura 6) en el cual cada alumno experimentaba una experiencia diferente dentro del mismo juego.

H5P permitía, además, definir diferentes escenarios de finalización con distintas calificaciones asociadas a las posibles ramas. De esta forma se pudo implementar el sistema de puntuaciones establecido, propuesto en la fase de desarrollo de los escenarios, y que permitía obtener datos objetivos del desempeño del alumno al resolver las situaciones planteadas.

Figura 6. Diseño del escenario «Entrevista por competencias»

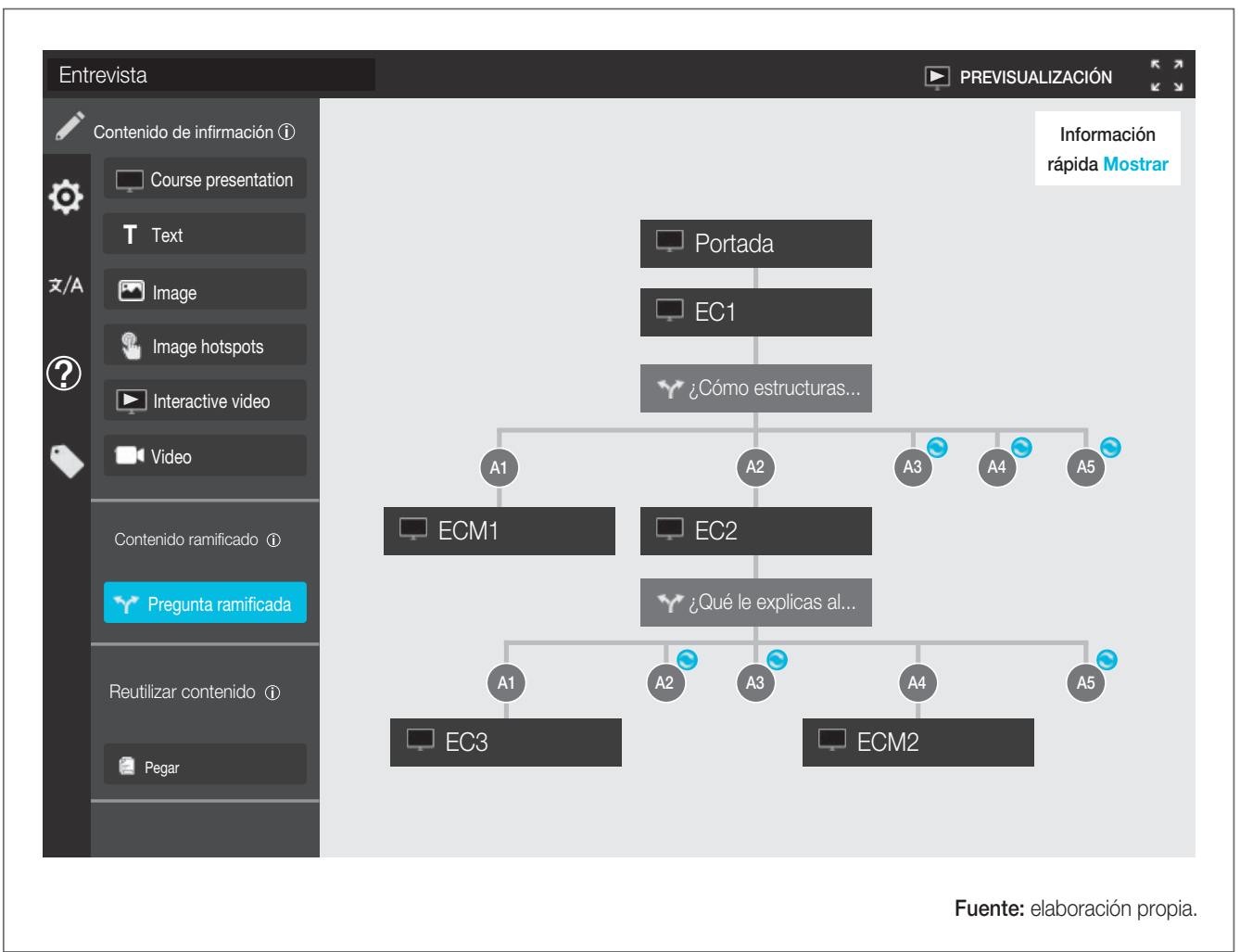


Una de las ventajas del uso de H5P es que el diseño del juego es completamente adaptativo, permitiendo a los estudiantes jugar con todo tipo de dispositivos móviles y desde cualquier lugar (véase figura 7).

Figura 7. Vista del juego desde un navegador web (izqda.) y desde el dispositivo móvil (dcha.)

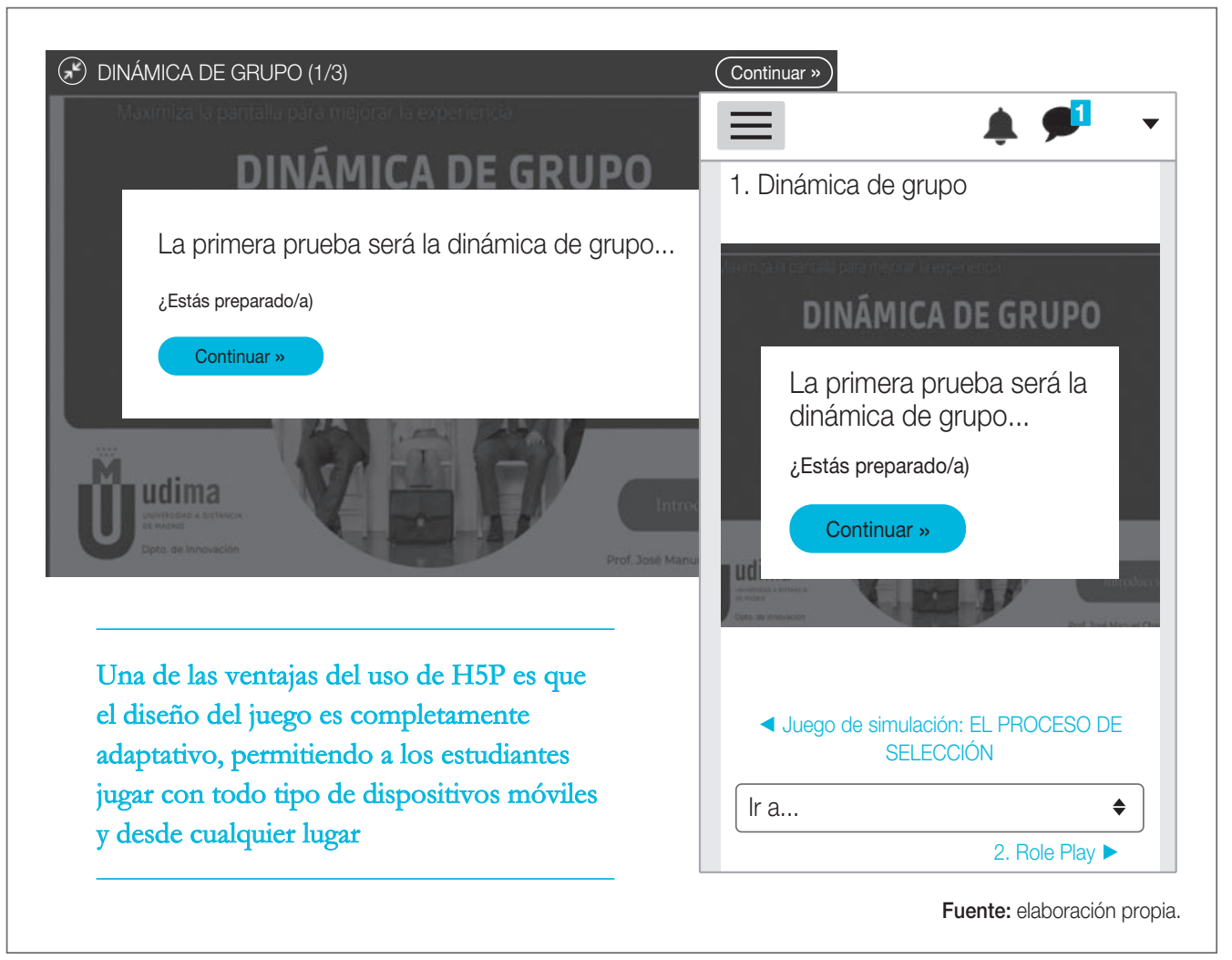

\subsection{Desarrollo de la actividad con los discentes}

La actividad se implementó en el aula virtual de la Bolsa de Empleo de la universidad, separando los escenarios principales en tres juegos diferentes, correspondientes a los tres procesos de selección, pero integrándolos en una página HTML como un único juego (véase figura 8). Salvo en la primera prueba, para acceder a cada una de ellas se exigía superar la anterior (véase figura 9).
La actividad se implementó en el aula virtual de la Bolsa de Empleo de la universidad, separando los escenarios principales en tres juegos diferentes, correspondientes a los tres procesos de selección 
Figura 8. Vista general del juego

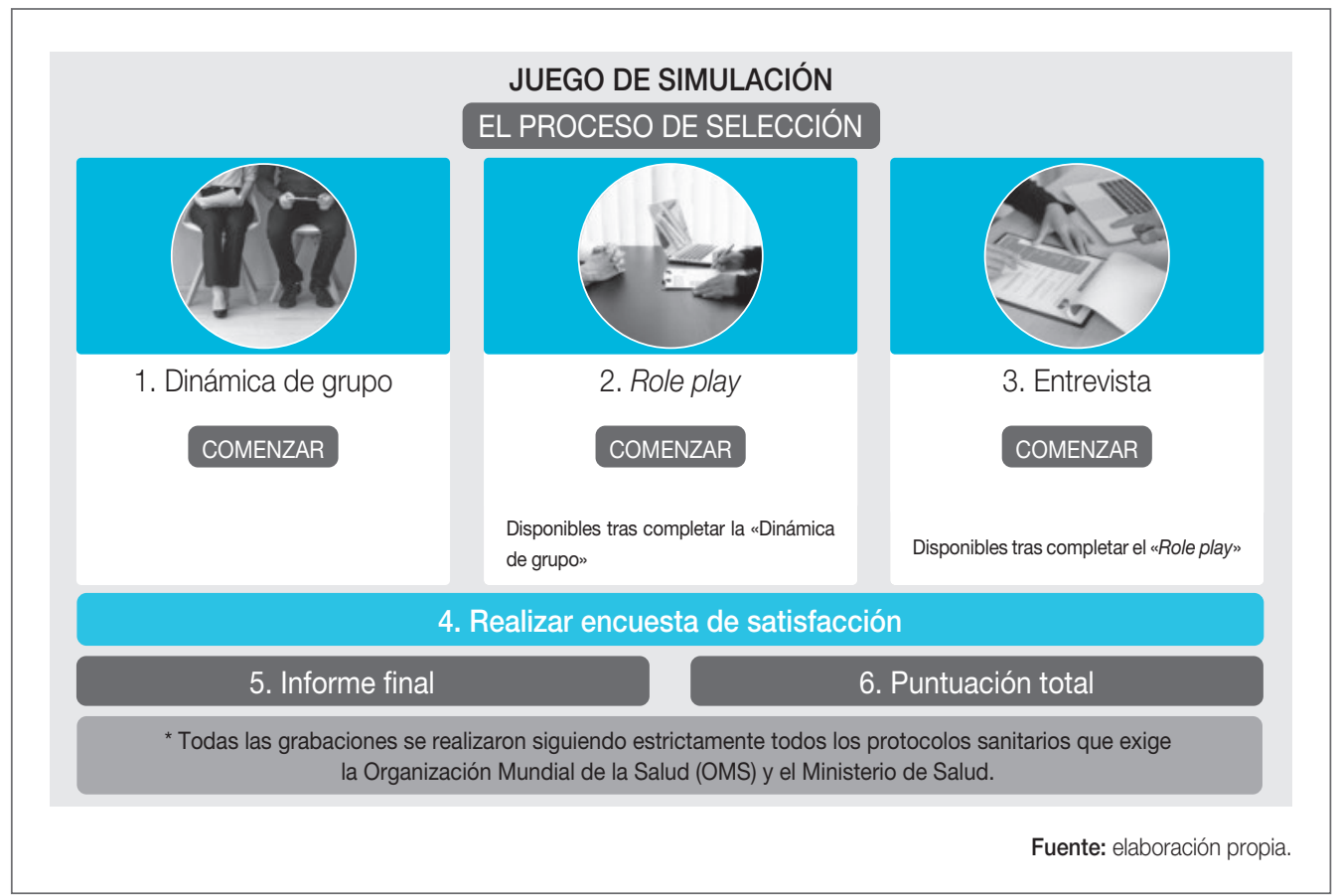

Figura 9. Escena del juego

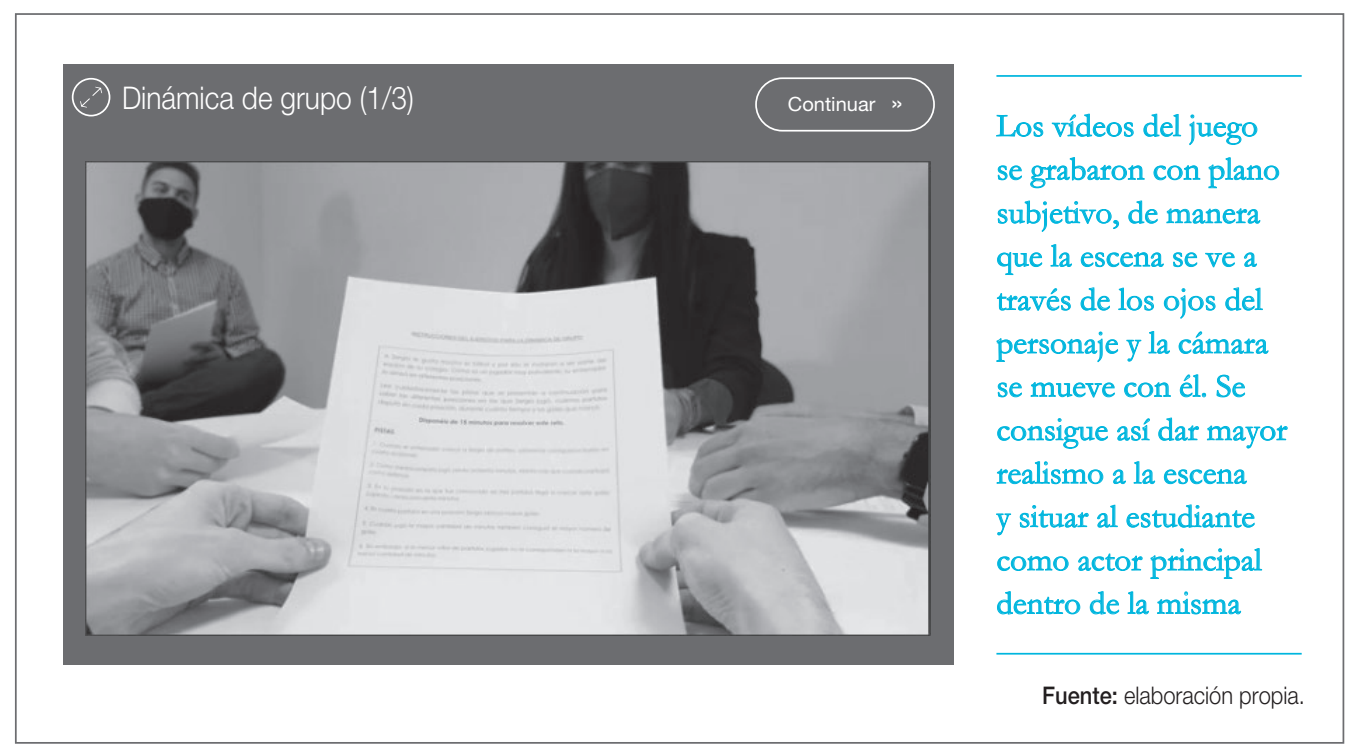


Además de los tres juegos, se incluía un hiperenlace a una encuesta de autopercepción para verificar, a través de las respuestas de los estudiantes, si se habían alcanzado los objetivos propuestos. La encuesta, elaborada a través de Google Forms, incluía, además de las preguntas de carácter sociodemográfico, las cuestiones que se pueden ver en la figura 10:

Figura 10. Preguntas de la encuesta elaborada con Google Forms

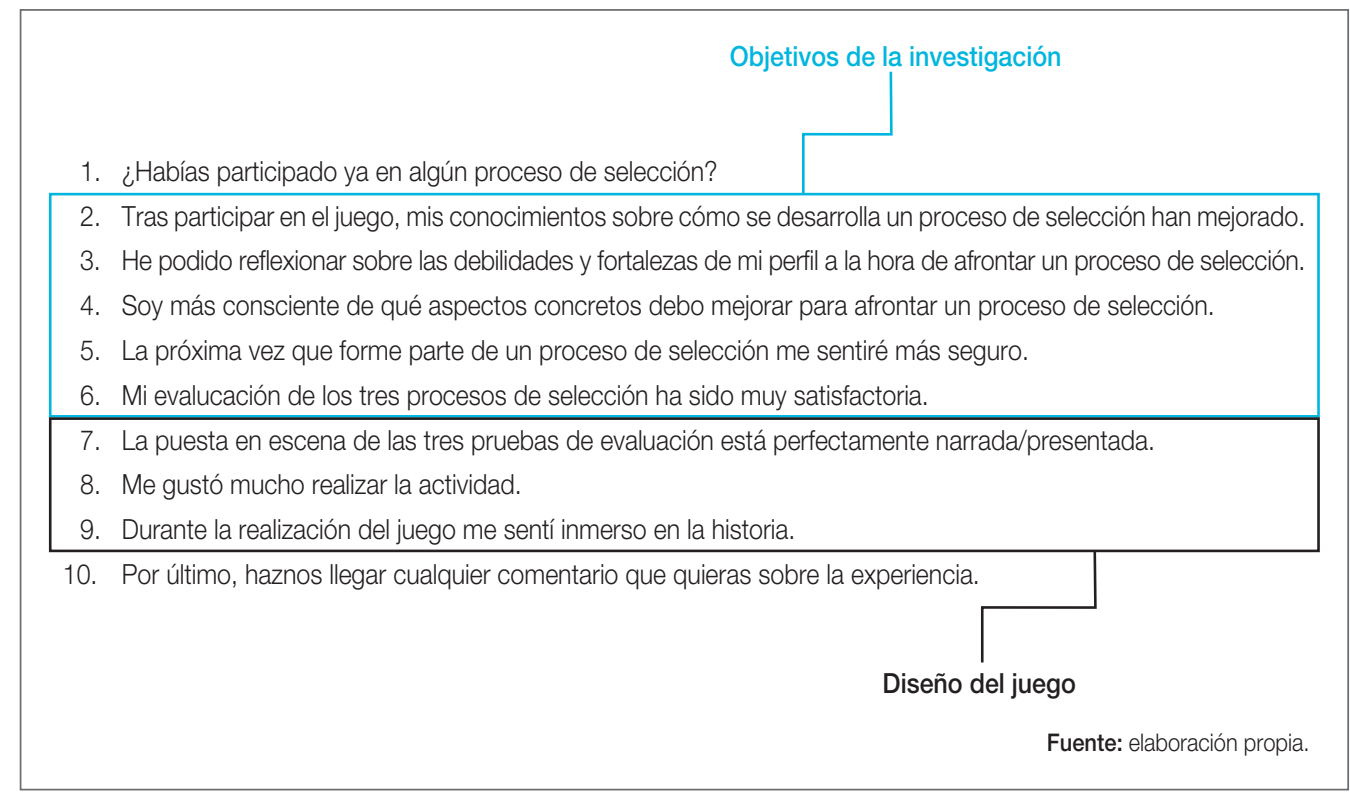

A excepción de la primera y última pregunta, el resto fueron respondidas por los estudiantes dentro de una escala Likert de 5 puntos: 1 (totalmente en desacuerdo), 2 (en desacuerdo), 3 (neutral), 4 (de acuerdo) y 5 (totalmente de acuerdo). Las preguntas 2 a 6 buscaban contrastar si se cumplían los objetivos de la investigación y las preguntas 7 a 9 , valorar si la realización del juego era suficientemente coherente, interesante y atractiva o si era necesario realizar algún ajuste para futuras fases del proyecto, tal y como se ha indicado en el apartado relativo al diseño tecnopedagógico. Para garantizar, en la medida de lo posible, su realización, se estableció como obligatorio si querían obtener el informe final y la calificación total global.

Una vez superados los tres escenarios y cumplimentada la encuesta, se concedió acceso automático al informe final. El objetivo de este informe era mejorar la experiencia de aprendizaje implícita en el juego, incluyéndose una descripción de cada uno de los escenarios, con especial énfasis en las competencias que se miden en cada uno de ellos, así como todas las preguntas y respuestas que los conforman, indicando, en cada caso, cuál hubiera sido la respuesta más adecuada y su justificación. 


\section{Análisis de los resultados obtenidos}

Para cada una de las preguntas que se midieron en el estudio a través de la escala Likert de 5 niveles, se calcula el error de estimación para un nivel de confianza del $95 \%$, de acuerdo a la siguiente fórmula original:

$$
E E=t_{0,975,(n-1)} \sqrt{\left(1-\frac{n}{N}\right)\left(\frac{P \times(100-P)}{n-1}\right)}
$$

Esta fórmula se ha modificado para maximizar el error y asumir, en parte, el sesgo de autoselección que afecta a este tipo de encuestas, que son respondidas voluntariamente por los estudiantes, de modo que el error de estimación depende solamente del número de alumnos llamados a realizar la encuesta (los que han jugado completamente el juego) y del número de encuestas recibidas:

$$
E E=t_{0,975,(n-1)} \sqrt{\left(1-\frac{n}{N}\right)\left(\frac{50^{2}}{n-1}\right)}
$$

Donde:

- $t=$ Percentil 97,5 de la distribución $t$-Student con $n-1$ grados de libertad.

- $n=$ Número de estudiantes que han respondido la encuesta.

- $N=$ Número de estudiantes totales que han jugado completamente el juego.

En este caso, la aplicación de la fórmula para los 74 estudiantes que han jugado el juego y para los 54 que han respondido la encuesta da un error de estimación del 7,03\%. La significación de los resultados obtenidos es alta, al encontrarse el error de estimación entre el 6 y el $8 \%$.

En general, los valores promedios alcanzados en los ítems de la encuesta son bastante positivos. Tal y como podemos ver en la figura 11, el 69,80\% del total de los participantes se mostró de acuerdo o totalmente de acuerdo con que sus conocimientos sobre cómo se desarrolla un proceso de selección habían mejorado tras participar en el juego (es decir, un total de 37 participantes estuvieron de acuerdo o totalmente de acuerdo). La puntuación media de esta pregunta es de 3,93 puntos sobre 5 en la escala Likert. 
Figura 11. «Tras participar en el juego, mis conocimientos sobre cómo se desarrolla un proceso de selección han mejorado»

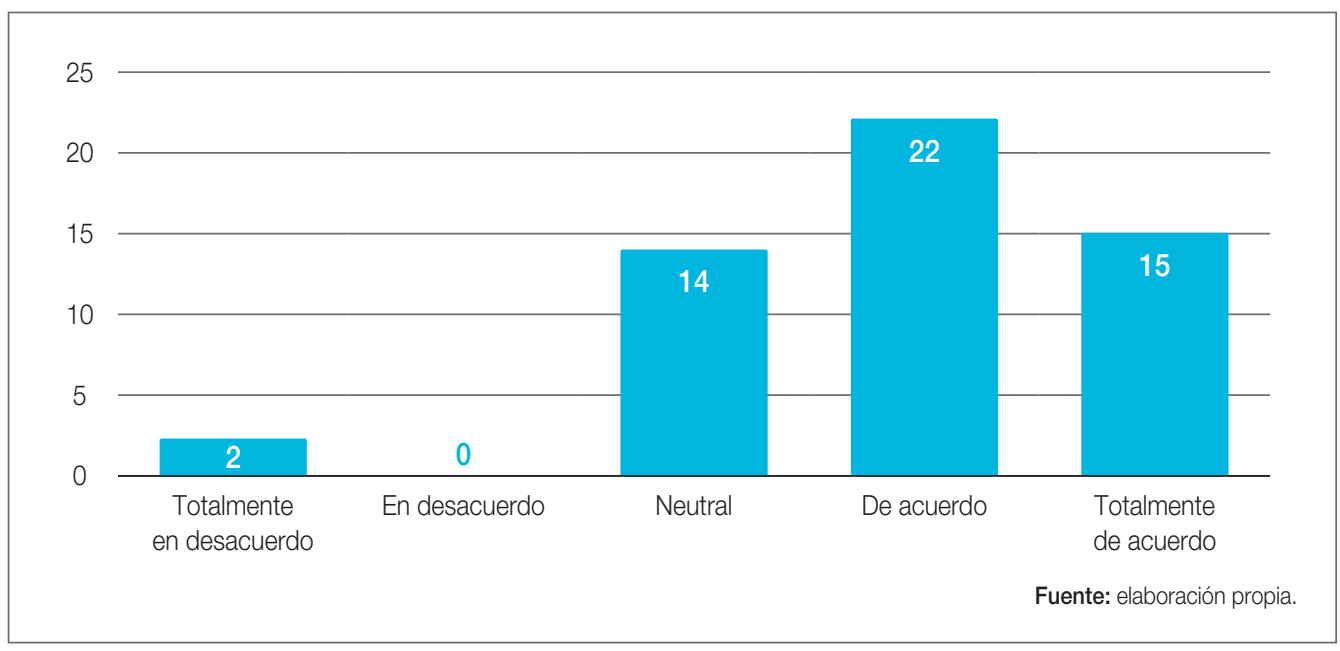

El porcentaje de estudiantes que estuvieron de acuerdo o totalmente de acuerdo con que el juego les permitía reflexionar sobre las debilidades y fortalezas de su perfil a la hora de afrontar un proceso de selección (véase figura 12) sube ligeramente al 72,20\% (es decir, un total de 39 participantes estuvieron de acuerdo o totalmente de acuerdo), siendo la puntuación media de esta pregunta 3,85 puntos sobre 5 .

Figura 12. «He podido reflexionar sobre las debilidades y fortalezas de mi perfil a la hora de afrontar un proceso de selección”

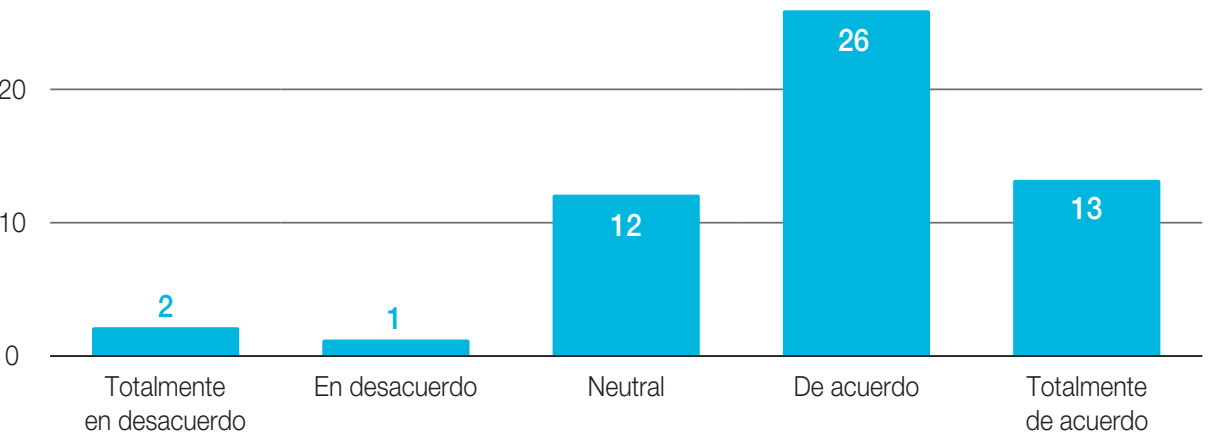

Fuente: elaboración propia. 
Como se puede ver en la figura 13 , el $68,50 \%$ de los participantes estuvo de acuerdo o totalmente de acuerdo en que eran más conscientes de qué aspectos concretos debían mejorar para afrontar un proceso de selección (es decir, un total de 37 participantes estuvieron de acuerdo o totalmente de acuerdo). La puntuación media de esta pregunta en la escala Likert fue de 3,85 puntos sobre 5 .

Figura 13. «Soy más consciente de qué aspectos concretos debo mejorar para afrontar un proceso de selección”

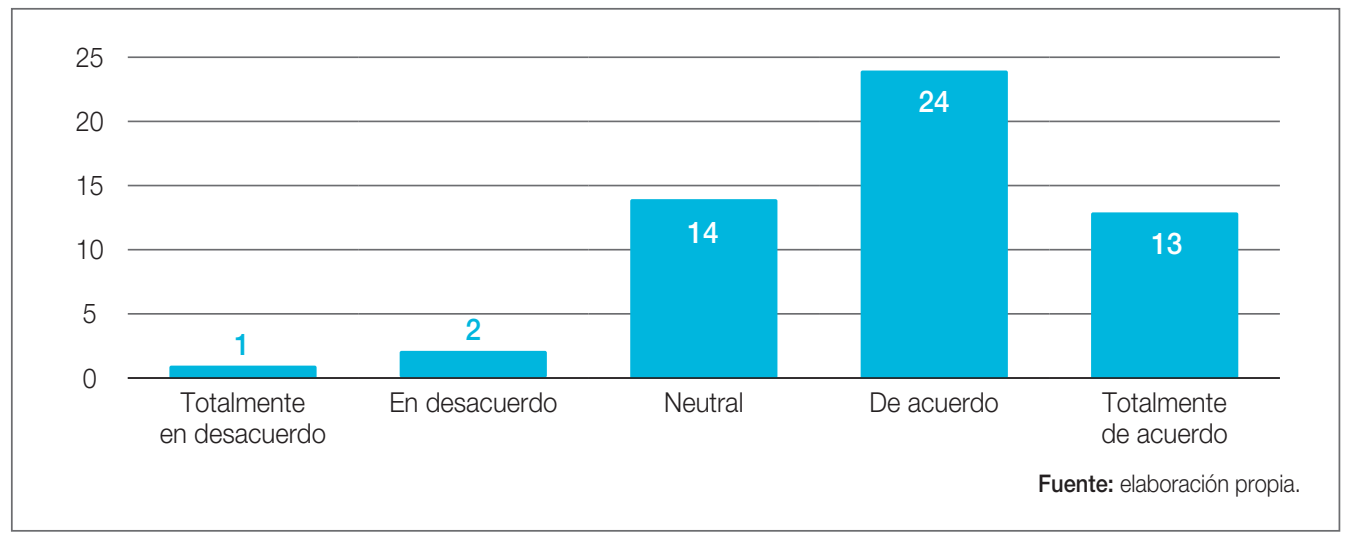

En relación con la seguridad percibida por los estudiantes a la hora de afrontar un proceso de selección, como se observa en la figura 14, el 70,30 \% declaró sentirse más seguro (es decir, un total de 38 participantes estuvieron de acuerdo o totalmente de acuerdo). La puntuación media de esta pregunta en la escala Likert fue de 3,81 puntos sobre 5.

Figura 14. «La próxima vez que forme parte de un proceso de selección me sentiré más seguro»

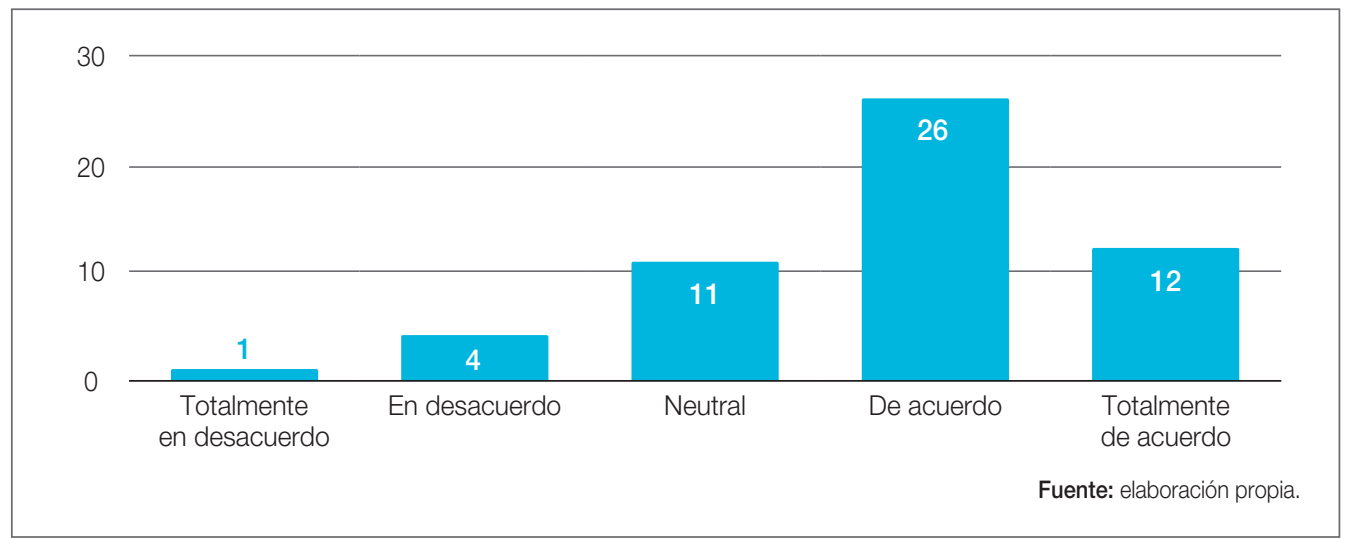


En lo relativo al diseño del juego, y de cara a seguir usándolo o mejorándolo en futuras fases de la investigación, interesaba valorar si la experiencia les había resultado narrativamente coherente, si se implicaron en su realización y si les gustó participar en ella.

En la figura 15 podemos ver que el $90,70 \%$ de los estudiantes estuvo de acuerdo o totalmente de acuerdo en que los tres escenarios principales estaban perfectamente presentados (es decir, un total de 49 participantes estuvieron de acuerdo o totalmente de acuerdo). Al 79,60\% les gustó mucho realizar esta actividad, sintiéndose inmersos en la historia (es decir, un total de 43 participantes estuvieron de acuerdo o totalmente de acuerdo) (véanse figuras 16 y 17).

Figura 15. «La puesta en escena de las tres pruebas de evaluación está perfectamente narrada/ presentada"

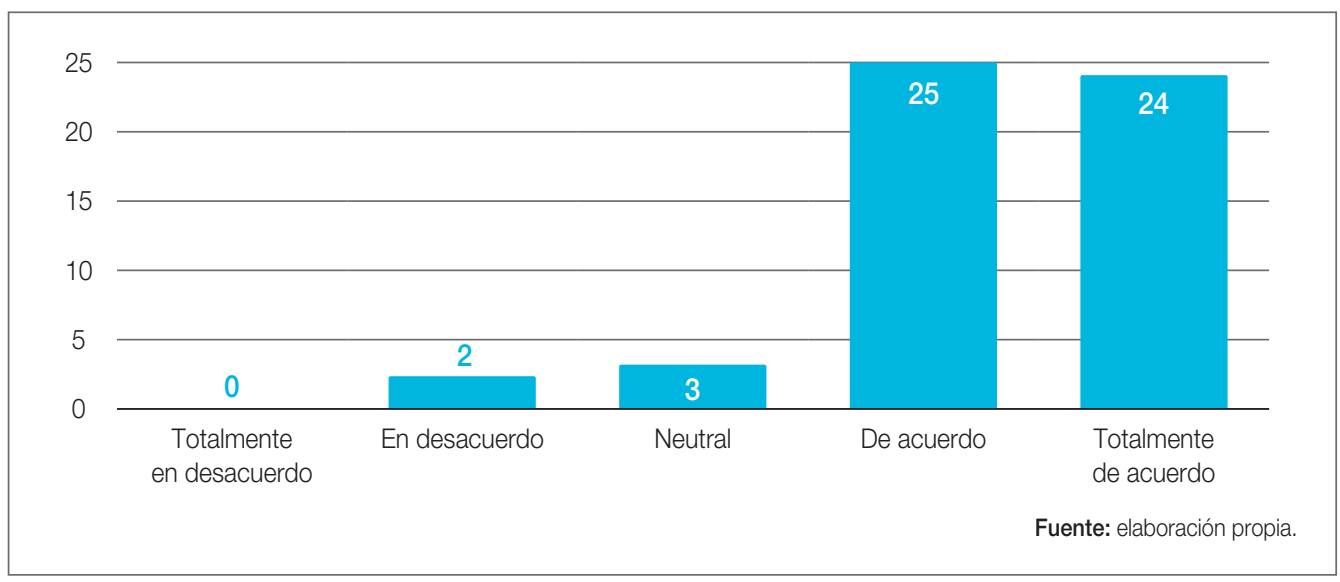

Figura 16. «Me gustó mucho realizar esta actividad»

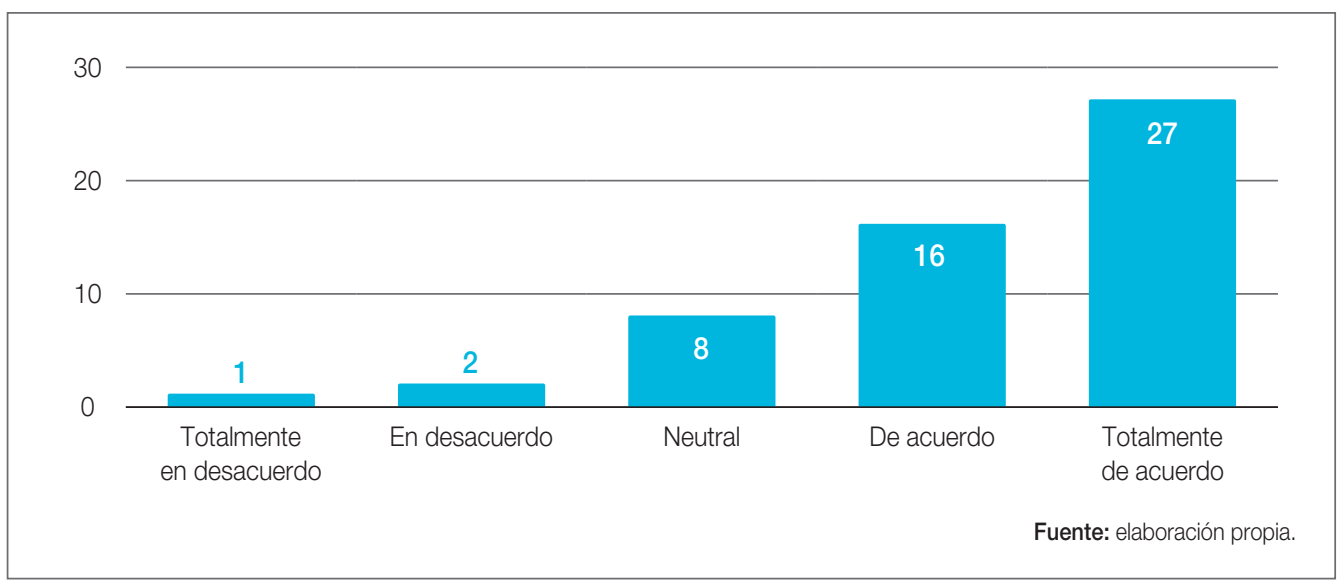


Figura 17. «Durante la realización del juego me sentí inmerso en la historia»

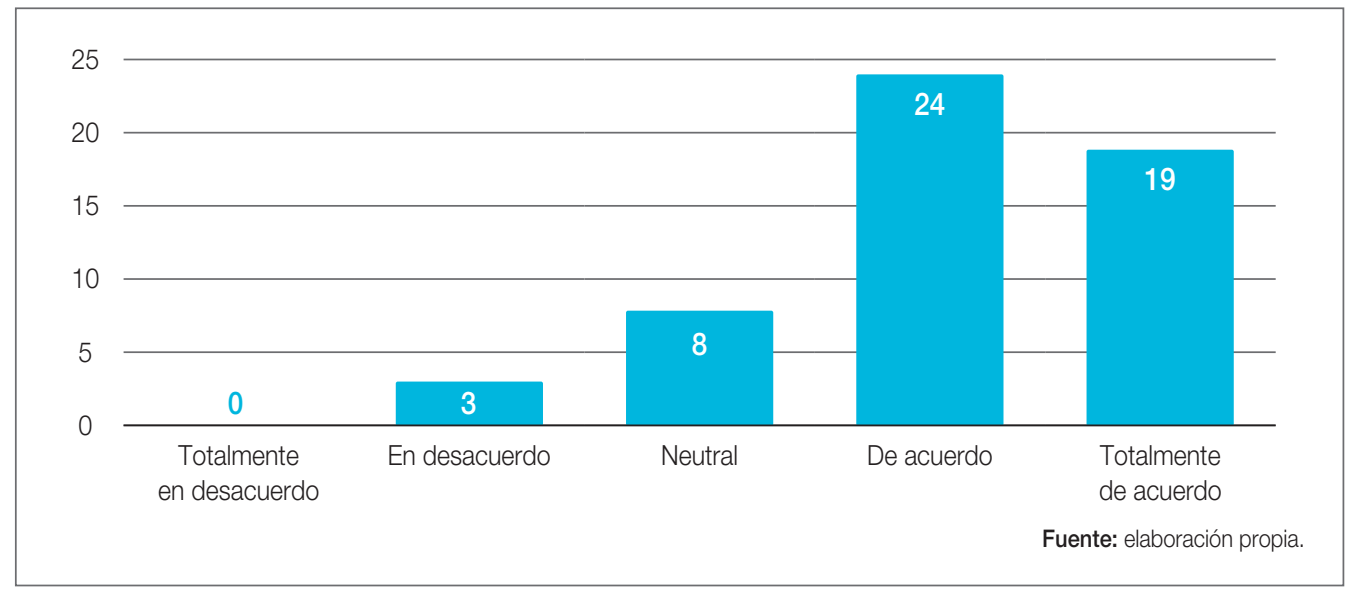

Por último, en la figura 18 observamos que la evaluación que hizo el 83,10\% de los participantes de los tres procesos de selección fue muy satisfactoria (es decir, un total de 44 participantes estuvieron de acuerdo o totalmente de acuerdo), obteniendo esta pregunta una media de 4,11 puntos sobre 5 en la escala Likert.

Figura 18. «Mi evaluación de los tres procesos de selección ha sido muy satisfactoria»

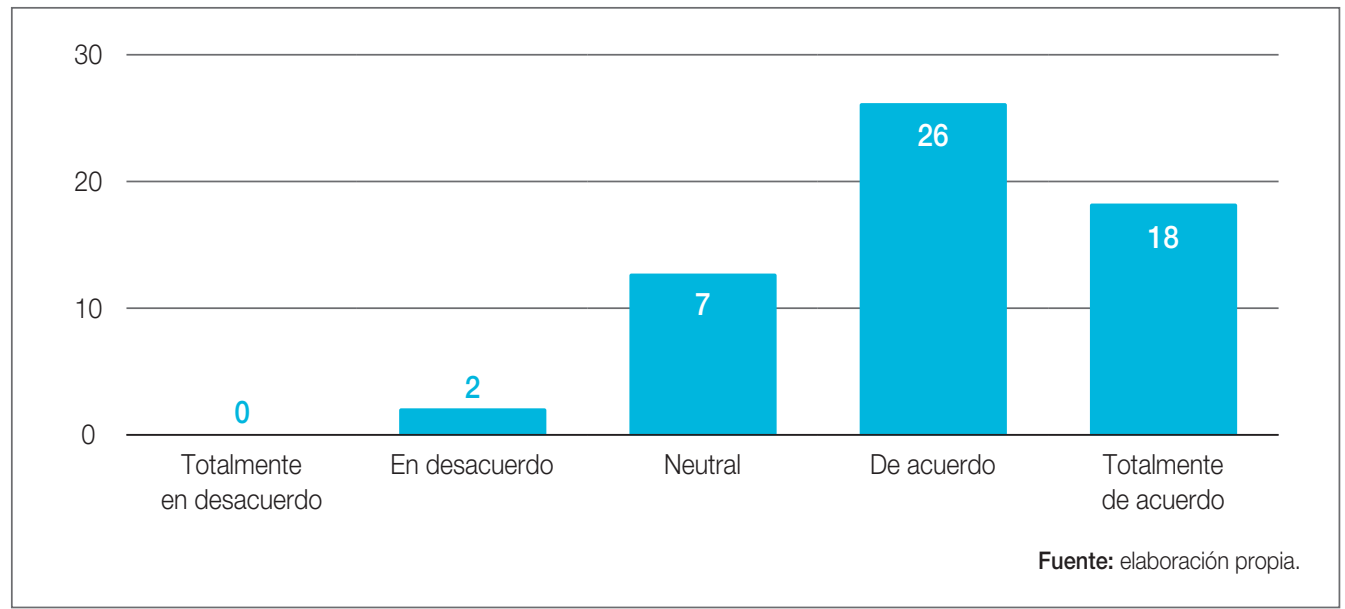

En los comentarios adicionales que los estudiantes enviaron a través de la última pregunta (disponibles todos ellos en el anexo final), se destaca el aspecto innovador de la experiencia, así como el interés que la misma tiene para un candidato, de cara a conocer mejor las pruebas de selección. Aunque el 73,60 \% había participado ya en algún proceso 
de selección (véase figura 19), algunos de ellos puntualizaron que nunca habían participado en una dinámica de grupo o en un role playing, dato lógico, al ser la entrevista el instrumento más conocido y utilizado en los procesos de selección de personal.

Figura 19. «¿Habías participado ya en algún proceso de selección?»

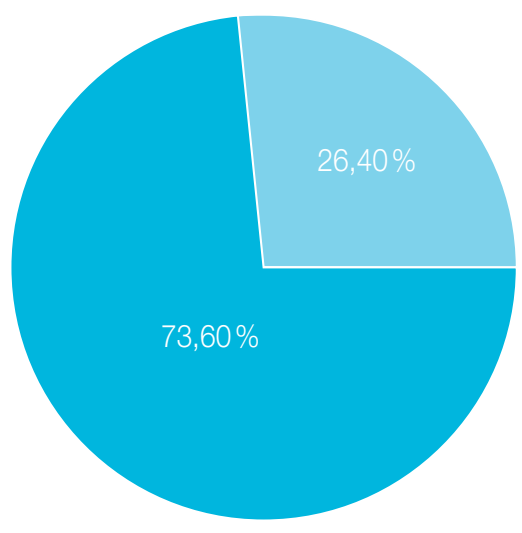

Sí he participado anteriormente en algún proceso de selección.

No he participado anteriormente en ningún proceso de selección.

\section{Conclusiones y futuras líneas de investigación}

El uso de un juego de simulación, fundamentado en el $A B E$, resulta de interés como herramienta de desarrollo de competencias para afrontar un proceso de selección de personal. Tras su aplicación en un entorno de enseñanza online con estudiantes de grado y máster, se ha confirmado que, desde su propia percepción, la participación en el juego les ayuda a mejorar sus conocimientos sobre cómo se desarrollan este tipo de procesos y sus diferentes pruebas. Además, la mayoría de ellos reconoce haber podido reflexionar sobre las debilidades y fortalezas de su perfil, identificando mejor aquellos aspectos concretos que deben mejorar. Por último, se confirma que tras intervenir en el juego, los estudiantes perciben una mayor seguridad para afrontar futuros procesos.

El uso de un juego de simulación,
fundamentado en el ABE, resulta de
interés como herramienta de desarrollo
de competencias para afrontar un
proceso de selección de personal. Tras
su aplicación en un entorno de enseñanza
online con estudiantes de grado y máster,
se ha confirmado que, desde su propia
percepción, la participación en el juego
les ayuda a mejorar sus conocimientos
sobre cómo se desarrollan este tipo
de procesos y sus diferentes pruebas

El uso de un juego de simulación, fundamentado en el $\mathrm{ABE}$, resulta de interés como herramienta de desarrollo de competencias para afrontar un su aplicación en un entorno de enseñanza online con estudiantes de grado y máster, se ha confirmado que, desde su propia percepción, la participación en el juego les ayuda a mejorar sus conocimientos de procesos y sus diferentes pruebas 
En futuras fases del proyecto se quiere mejorar la estructura técnica del juego, con opciones más avanzadas de navegación e interfaz. Con respecto al diseño de las situaciones y pruebas de selección, se pueden orientar hacia lo que sería un test de juicio situacional, ya que se ha evidenciado que tiene una alta validez predictiva de criterio y muestra buena predictibilidad del rendimiento con la competencia que se pretenda medir. Este paso supondría también incorporar elementos de valor añadido (gráficos, rating por competencia, etc.) en el diseño de los informes de resultados, más ajustados a los objetivos de identificación y desarrollo de las capacidades de los alumnos. Las líneas de investigación que se abren después de este trabajo son la ampliación de la muestra de estudiantes para verificar que se mantienen las hipótesis contrastadas y la estratificación por grupos de edad y titulación, para verificar si existen diferencias significativas en los resultados. Por último, resultaría de interés medir el impacto en estudiantes que vayan a realizar un proceso de selección en un plazo corto de tiempo, después de la participación en el juego, de manera que pueda trascenderse la autopercepción del estudiante y verificarse su efectividad en el contexto real.

\section{Referencias bibliográficas}

Alonso, P., Moscoso, S. y Cuadrado, D. (2015). Procedimientos de selección en pequeñas y medianas empresas españolas. Revista de Psicología del Trabajo y de las Organizaciones, 31(2), 79-89.

Breakey, K. M., Levin, D., Miller, I. y Hentges, K. E. (2008). The use of scenario-basedlearning interactive software to create custom virtual laboratory scenarios for teaching genetics. Genetics, 179(3), 1.151-1.155.

Cant, R. P. y Cooper, S. J. (2010). Simulationbased learning in nurse education: systematic review. Journal of Advanced Nursing, 66(1), 3-15.

Carr, P. B. y Walton, G. M. (2014). Cues of working together fuel intrinsic motivation. Journal of Experimental Social Psychology, 53, 169-184.

Carrero-Sánchez, J. (2011). Introducción a la educación mediática infantil: el diseño del
Storyboard. Revista de la SEECl, 15(24), 69-83. https://cutt.ly/xbwFeJT

Clark, R. C. y Mayer, R. E. (2012). ScenarioBased E-Learning: Evidence-Based Guidelines for Online Workforce Learning. John Wiley \& Sons.

Choragwicka, B. y Moscoso, S. (2007). Validez de contenido de una entrevista conductual estructurada. Revista de Psicología del Trabajo y de las Organizaciones, 23(1), 75-92.

Errington, E. (2011). As Close as it Gets: Developing Professional Identity Through the Potential of Scenario-Based Learning. Surrey Centre for Excellence in Professional Training and Education.

Flanagan, J. C. (1954). The critical incident technique. Psychological Bulletin, 51(4), 327-358.

Hursen, C. y Fasli, F. G. (2017). Investigating the efficiency of scenario based learning and 
reflective learning approaches in teacher education. European Journal of Contemporary Education, 6(2), 264-279. https://eric. ed.gov/?id=EJ1146153

Janz, T. (1982). Initial comparisons of patterned behavior description interview versus unstructured interviews. Journal of Applied Psychology, 67(5), 577-580.

Janz, T. (1989). The Patterned Behavior Description Interview: The best prophet of the future is the past. En R. W. Eder y G. R., Ferris (Eds.). The Employment Interview: Theory, Research and Practise (pp. 158168). Sage.

Martínez Caro, E. (2009). La gestión del conocimiento a través del e-learning. Un enfoque basado en escenarios. Investigaciones Europeas de Dirección y Economía de la Empresa, 15(1), 29-44. https://cutt.ly/ibw $\mathrm{DZBr}$

McClelland, D. C. (1973). Testing for competence rather than for «intelligence». American Psychologist, 28(1), 1-14.

McLaren, A. C. (2008). Design effective e-learning. Guidelines for practitioners. Distance Learning, 5(2), 47-57. https://cutt.ly/ybwFzko

Medrano, C. (2009). El Storyboard. https://scho lar.googleusercontent.com/scholar?q= cache:OAOEV92-0EEJ:scholar.google.com/ +Medrano,+C.+(2009).+El+Storyboard.\&hl $=$ es\&as_sdt $=0,5$

Motowidlo, S. J., Carter, G. W., Dunette, M. D., Tippins, N., Werner, S., Burnett, J. R. y Vaughan, J. (1992). Studies of structured behavioral interview. Journal of Applied Psychology, 77(5), 571-588.

Muhamad, M., Zaman, H. B. y Ahmad, A. (2012). Virtual biology laboratory (VLab-Bio): scenario-based learning approach. Procedia-Social and Behavioral Sciences, 69, 162-168.
Mulder, M. (2007). Competencia: la esencia y la utilización del concepto en la formación profesional inicial y permanente. Revista Europea de Formación Profesional, 40, 5-24.

Nickson, A. (2010). Social Work Ethics in Scenario Based Learning. Post Pressed.

Papadimitriou, A. (2012). A scenario-based learning of electrical circuits. Journal of Education and Practice, 3(7), 27-45.

Proudfoot, D. E. y Kebritchi, M. (2017). Scenariobased elearning and stem education: a qualitative study exploring the perspectives of educators. International Journal of Cognitive Research in Science, Engineering and Education, 5(1), 7-18.

Romeo Delgado, M. y Yepes i Baldó, M. (2005). Estudio comparativo de competencias. En J. Romay Martínez (Ed.), R. García Mira (Ed.) y J. E. Real Deus (Comp.), Psicología del trabajo en el ámbito de las relaciones laborales. Vol. 4. Psicología de las organizaciones, del trabajo y recursos humanos y de la salud (pp. 25-32). Biblioteca Nueva.

Romero Santos, D., Cordon, C. R. y PalomoDuarte, M. (2019). Extending H5P Branching Scenario with $360^{\circ}$ scenes and XAPI capabilities: a case study in a local networks course. 2019 International Symposium on Computers in Education (SIIE) (pp. 1-6). IEEE. https://cutt.ly/abwDYc9

Rosario Ahumada, V. del. (2013). El aprendizaje basado en escenarios (ABE). Metodologías, Estrategias y Herramientas Didácticas para el Diseño de Cursos en Ambientes Virtuales de Aprendizaje en la Universidad Nacional Abierta y a Distancia UNAD, 55-62. https:// cutt.ly/JbwD9ni

Salgado, J. F. y Moscoso, S. (1995). Validez de las entrevistas conductuales estructuradas. Psicología del Trabajo y las Organizaciones, 11(31), 9-24. 
Salgado, J. F. y Moscoso, S. (2001). Entrevista conductual estructurada de selección de personal: teoría, práctica y rentabilidad. Pirámide.

Salgado, J. F. y Moscoso, S. (2002). Comprehensive metaanalysis of the construct validity of the employment interview. European Journal of Work and Organizational Psychology, 11(3), 299-324.

Salgado, J. F. y Moscoso, S. (2006). Utiliser les entretiens comportementaux structurés pour la sélection du personnel? En C. Lévy-Leboyer, C. Louche y J. P. Rolland (Eds.), RH: Les apports de la psychologie du travail (Vol. 1, pp. 195-207). Éditions d'Organisation.

Salgado, J. F. y Moscoso, S. (2008). Selección de personal en la empresa y las Administraciones públicas: de la visión tradicional a la visión estratégica. Papeles del Psicólogo, 29(1), 16-24.

Salgado, J. F. y Moscoso, S. (2011). Entrevista conductual estructurada de selección de personal: teoría, práctica y rentabilidad (3. ${ }^{a}$ ed.). Pirámide.

Salgado, J. F., Gorriti, M. y Moscoso, S. (2007). La entrevista conductual estructurada y el desempeño laboral en la Administración pública española: propiedades psicométricas y reacciones de justicia. Revista de Psicología del Trabajo y las Organizaciones, 23(1), 39-55.

Salgado, J. F., Moscoso, S. y Gorriti, M. (2004). Investigaciones sobre la entrevista conductual estructurada (ECE) en la selección de personal en la Administración general del País Vasco: metaanálisis de la fiabilidad. Revista de Psicología del Trabajo y las Organizaciones, 20(2), 107-139.
Schank, R. C. (1997). Virtual Learning: A Revolutionary Approach to Building a Highly Skilled Workforce. McGraw-Hill.

Schank, R. C. y Cleary, C. (1995). Engines for Education. Lawrence Erlbaum Associates.

Spencer, L. M. y Spencer, S. M. (1993). Competence at Work: models for Superior Performance. John Wiley \& Sons, Inc.

Steadman, R. H., Coates, W. C., Huang, Y. M., Matevosian, R., Larmon, B. R., McCullough, L. y Ariel, D. (2006). Simulation-based training is superior to problem-based learning for the acquisition of critical assessment and management skills. Critical Care Medicine, 34(1), 151-157.

Taylor, P. J. y Small, B. (2002). Asking applicants what they would do versus what they did do: a meta-analytic comparison of situational and past behaviour employment interview questions. Journal of Occupational and Organizational Psychology, 75, 277-294.

Vossio, B. R. (2002). Certificación y normalización de competencias. Orígenes, conceptos y prácticas. Boletín Cinterfor, 152, 51-73.

World Economic Forum. (2020). The Future of Jobs Report.

Yániz Álvarez de Eulate, C. y Villardón Gallego, L. (2006). Planificar desde competencias para promover el aprendizaje. El reto de la sociedad del conocimiento para el profesorado universitario. Cuadernos Monográficos del ICE, 12. Universidad de Deusto; Servicio de Publicaciones.

Zabala, A. y Arnau, L. (2008). 11 ideas clave: cómo aprender y enseñar competencias. Graó. 


\section{ANEXO \\ Comentarios adicionales recibidos en la encuesta de autopercepción}

- «Innovadora la forma de enfocar las tres pruebas y muy interesantes las preguntas realizadas por el "director general"».

- «Me ha encantado poder explorar mediante esta simulación el proceso de selección, ya que se cogen ideas y tips ocurrentes para realizar una efectiva entrevista cuando surja la oportunidad. Además, esta enseñanza a distancia debe trasladar de una manera más cercana y real conocimientos al estudiante para que, así, este tipo de enseñanzas e-learning sean efectivas».

- «En mi vida laboral he realizado varias entrevistas de trabajo, pero nunca me había enfrentado a una dinámica de grupo ni a un role play».

- «Es cierto que, al tener respuestas acotadas, es más fácil acertar y, en la realidad, tienes que enfrentarte al vacío de tu mente».

- «En cualquier caso, me parece una muy buena simulación para conocer los procesos de primera mano, enfrentarte a ellos desde casa y aprender qué tipo de respuestas son las más adecuadas".

- "La verdad es que me ha gustado mucho la actividad. En la parte de role play, me sentí un poco nervioso, ya que no sabía si estaba contestando bien a las preguntas, por los gestos muy serios de la presentadora, pero me pareció genial porque hace que te sientas inmerso en el juego».

- «En la parte tres, fue un poco confusa la pregunta de "¿Por qué no deberíamos contratarte?", pero, al final, estuvo bien, ya que supongo que en la vida real se dan estos casos y generan cierta confusión o nerviosismo en dichos procesos».

- «Muy bien. Me ha gustado. Faltaría quizás un apartado de iniciativa propia».

- «Buena iniciativa».

- «Congratulations. Good job».

- "Considero que es una experiencia gratificante, que me ha ayudado a comprender el funcionamiento de este tipo de procesos y a generar en mí un poco de confianza a la hora de afrontarlos».

- «Poder explicar con más detalles el porqué de una opción u otra».

- «Muy interesante. Puede aportar a la preparación del candidato. Gracias».

- «Ha sido una experiencia muy interesante. De todos los procesos en los que he participado nunca he realizado una dinámica de grupo. El resto de procesos son muy parecidos. Espero que me ayude a escuchar realmente ese mensaje en mi teléfono».

- «Me ha encantado».

- "Novedoso. Me ha gustado mucho».

- «He realizado procesos de selección, pero nunca como este juego. Me pareció muy interesante». 